\title{
Cationic polymers in water treatment Part 1: Treatability of water with cationic polymers
}

\author{
P Polasek ${ }^{1 *}$ and S Mutl ${ }^{2}$ \\ ${ }^{1}$ P Polasek \& Associates, Consulting Engineers, P O Box 61965, Marshalltown 2107, South Africa \\ 2 Institute of Hydrodynamics, Academy of Sciences of the Czech Republic, Pod Patankou 5, 16612 Praha 6, Czech Republic
}

\begin{abstract}
This paper investigates the best attainable treatability to which a water polluted with a technologically significant concentration of organic matter is treatable by different cation-active polyelectrolytes and their blends with mineral coagulants in comparison to that attainable by traditional hydrolysing coagulants. The negative influence of these reagents used as primary coagulants on the treated water quality is demonstrated in the case of Saulspoort Waterworks.
\end{abstract}

\section{Introduction}

One of the prime objectives of water treatment is the removal of colloidal impurities of which organic matter is the most important. It should be emphasised that impurities of an organic nature are far more objectionable from a hygienic point of view than impurities of a mineral nature. Since organic matter can be precursors of organohalogens (carcinogens)(Hocman, 1986), water treatment technology design should always be aimed at achieving the maximum possible removal of organic matter (Polasek and Mangeot, 1988).

The substitution of traditional hydrolysing reagents by cationic polymers (CPE) is becoming increasingly popular in South Africa, although no comprehensive investigation into the suitability of $\mathrm{CPE}$ as primary coagulants and their possible side-effects has been carried out. The decision to substitute hydrolysing reagent with CPE is usually based on a simple comparison of reagent dosage costs. Another reason used is that $\mathrm{CPE}$ are more user-friendly, i.e. do not change water $\mathrm{pH}$ and are easier to handle.

There is relatively little information available in literature on the use of CPE as the primary coagulant and their effect of the final quality of treated water. Some information on this topic can be found in foreign articles (Narkis and Rebhun, 1977; Glazer and Edzwald, 1979; Amy and Chadik, 1983; Carns and Parker, 1985; Tanaka and Pirbazari, 1986; Aizawa et al., 1990; Gregory and Lee, 1990;) and only limited information is available in local articles (Healey et al., 1987; Nozaick et al., 2000a and Nozaick et al., 2000b; Pryor and Freese, 1999; Polasek and Mutl, 2000).

The authors have tested different CPE over many years at different localities in South Africa and verified the suitability of their application on some of the localities where CPE are in use (Polasek and Mutl, 1995b; Mutl and Polasek, 1996; Polasek and Mutl, 1997; Polasek and Mutl,1999). A comprehensive investigation into the treatability of water attainable with different CPE was carried out at Saulspoort Waterworks during 1993. The objective of this study was to establish the feasibility of using CPE for the treatment of water with a technologically significant organic content. The results obtained are presented in this paper. Part 1 of this article

* To whom all correspondence should be addressed.

政(011) 642-5727; fax: (011) 484-2187; e-mail: polasek@mweb.co.za Received 22 March 2001; accepted in revised form 30 September 2001. investigates the influence of CPE on the attainable treatability of water. Part 2 of the article investigates the influence of CPE-formed suspension on the performance of filters.

\section{Significance of organic pollution}

The most important organic pollution is produced by humic matter. Humic matter is the most significant precursor of organohalogens and other chlorine-derivates. Therefore, their presence in drinking water is undesirable. In natural waters humic matter occurs, depending on $\mathrm{pH}$ value, as negatively-charged macromolecules. The negative charge is caused by the presence of carboxyl and phenolic groups (-COOH and -OH). Both groups dissociate in an alkaline $\mathrm{pH}$ range in which humic acids dissolve readily. In an acidic $\mathrm{pH}$ range, humic acids do not dissociate and are poorly soluble. Therefore, they can only have a negative charge, the value of which decreases with a decreasing $\mathrm{pH}$ value. In surface waters, mixtures of different molecular and micellar colloids exist. Therefore, a compromise operational reaction $\mathrm{pH}$, at which the highest removal of organic impurities is achieved, together with operational dosage of primary coagulants are investigated by jar tests. Most organic impurities contained in water have an acidic character. Therefore, as a rule, the surface waters should be treated in an acidic $\mathrm{pH}$ range (Tucek et al., 1977).

The humic matter occurring in low molecular form cannot be removed from water by current chemical treatment (Pitter, 1981). Their removal necessitates the use of advanced treatment processes such as ozonation and activated carbon adsorption.

\section{Testing site}

The Saulspoort Waterworks belongs to the Municipality of Bethlehem. The source of raw water is the Saulspoort Dam fed by the Axel River and the Liebenberg Vlei, and is one of the most polluted waters in South Africa. Its turbidity fluctuates considerably throughout the year while organic pollution, characterised by a $\mathrm{COD}_{\mathrm{Mn}}$ value, is relatively high but fairly steady, varying between $\mathrm{COD}_{\mathrm{Mn}}=5$ to $7 \mathrm{mgO}_{2} \cdot \ell^{-1}$. For raw water data see Table 1 .

The design capacity of the Saulspoort Waterworks is $40 \mathrm{M} / \mathrm{d}$. The treatment process is based on a two-stage separation of the formed suspension. The flocculent suspension is formed under conditions of the Inline High Density Suspension (IHDS) process 


\begin{tabular}{|c|c|c|c|}
\hline \multicolumn{4}{|c|}{$\begin{array}{c}\text { TABLE 1 } \\
\text { Saulspoort Dam water analysis }\end{array}$} \\
\hline Determinant & Unit & Maximum & Minimum \\
\hline $\mathrm{pH}$ & {$[-]$} & 8.2 & 7.4 \\
\hline Colour & [HU] & 40 & 10 \\
\hline Turbidity & [NTU] & 250 & 20 \\
\hline Total Alkalinity & {$\left[\mathrm{mg} \mathrm{CaCO} \cdot \ell^{-1}\right]$} & 160 & 90 \\
\hline $\mathrm{Fe}$ & {$\left[\mathrm{mg} \cdot \ell^{-1}\right]$} & 1.5 & 0.5 \\
\hline $\mathrm{COD}_{\mathrm{Mn}}$ & {$\left[\mathrm{mg} \mathrm{O}_{2} \cdot \ell^{-1}\right]$} & \multicolumn{2}{|c|}{6.5 to $5.9 *$} \\
\hline
\end{tabular}

(Polasek and Mutl, 1995a; Polasek, 1970 and 1972). The formed suspension is first separated in a High Rate (HR) sludge blanket clarifier followed by filtration in rapid gravity dual media filters. The first separation process unit consists of four HR clarifiers, each of a diameter $\mathrm{D}_{\mathrm{CL}}=8.65 \mathrm{~m}$. The $\mathrm{HR}$ clarifier incorporates flocculation, sludge blanket, treated water and sludge thickening compartments. No lamella or similar facility forms part of the clarifier design. Each clarifier with a capacity $\mathrm{Q}=10 \mathrm{M} / \mathrm{d}$, is designed for an upflow velocity $\mathrm{v}_{\mathrm{SB}}=11 \mathrm{~m} / \mathrm{h}$ at the sludge blanket level. It was successfully tested at $50 \%$ hydraulic overload. The removed sludge is first thickened in the sludge compartment up to $75 \mathrm{~g} \cdot \ell^{-1}$ (Polasek and van Duuren, 1981) prior to its discharge from the clarifier for further dewatering. The second separation process unit, filtration, consists of eight dual media filters, each designed for a filtration velocity of $\mathrm{v}_{\mathrm{F}}=10 \mathrm{~m} / \mathrm{h}$. At the time of testing, CPE L-100 was used at the waterworks as the coagulant.

\section{Jar tests and their evaluation}

The treatment process efficiency attainable by different CPE was investigated by jar tests. CPE, both natural and synthetic, and commercially available blended CPE were tested. The CPE of synthetic origin were represented by polyamine and polydiallyldimethylammonium chloride (polyDADMAC) - probably the most widely used cationic polyelectrolyte in water treatment today. The CPE of natural origin was represented by Belfloc, a blend of Floccotan (a partially condensed product of commercial wattle tannin extract treated to produce active amine groups along the polymerised molecule) and polyDADMAC.

In order to obtain a reference datum to which treatability of the water obtained with CPE could be compared, traditionally used hydrolysing reagents, namely ferric chloride and aluminium sulphate, together with polyaluminium chloride $(\mathrm{PACl})$, were also tested.

The unwillingness of the CPE suppliers to provide technical specifications and basic information about their products which are important from the treatment process point of view made the evaluation of the efficiency of the treatment process considerably more difficult. Due to a lack of available information, the composition of the CPE tested had to be assessed. This assessment is based on the sketchy information obtained from different sources and the results of analysis obtained during testing.

The standard jar test operation and testing procedures adopted in this study are in accordance with the Guidelines to coagulation and flocculation for surface waters (Polasek P and Mutl S 1995). All jar tests were carried out under the conditions of the IHDS process with 5 min rapid agitation at $\overline{\mathrm{G}} 200 \mathrm{~s}^{-1}$ followed by $10 \mathrm{~min}$

\begin{tabular}{|c|c|c|}
\hline \multicolumn{3}{|c|}{$\begin{array}{c}\text { TABLE } 2 \\
\text { The extent of secondary organic pollution } \\
\text { of the treated water caused by natural } \\
\text { CPE (Floccotan) at Saulspoort } \\
\text { Waterworks } \\
\text { (Private communication, 1983) }\end{array}$} \\
\hline Determinant & $\begin{array}{c}\mathrm{DOC} \\
{\left[\mathrm{mg} \mathrm{C} \cdot \mathrm{l}^{-1}\right]}\end{array}$ & $\underset{[\mathrm{mg} \mathrm{CHCl}}{\left.\mathrm{TOH}_{3} \cdot \ell^{-1}\right]}$ \\
\hline Raw water & 5.2 & 878 \\
\hline Flocculated water & 4.8 & 1211 \\
\hline Filtered water & 4.6 & 1209 \\
\hline
\end{tabular}

slow agitation at $\overline{\mathrm{G}} \approx 30 \mathrm{~s}^{-1}$.

The attainable treatability of the water was evaluated against the following three pollution determinants:

- cation of added hydrolysing reagent $\mathrm{Me}(\mathrm{Fe}$ or $\mathrm{Al})$ introduced into the water by the dosed coagulant,

- organic pollution characterised by $\mathrm{COD}_{\mathrm{Mn}}$ value, determined by the Kubel method (Kubel, 1866), and measured in accordance with the method described in Polasek and Mutl, 1995a and - turbidity (Tu).

The reaction $\mathrm{pH}$ was also monitored.

The methodology of sampling, analytical processing of samples and evaluation of the results obtained can be found in Guidelines to coagulation and flocculation for surface waters (Polasek and Mutl, 1995a). The $\mathrm{Tu}_{60} \mathrm{~F}$ and $\mathrm{Me}_{60} \mathrm{~F}$ are the residual turbidity and the concentration of cation of added hydrolysing reagent caused by their respective non-separable particles remaining in the treated water. They were measured in a sample of treated water taken after $1 \mathrm{~h}$ sedimentation from which the separable particles were removed by centrifugation. $\mathrm{The} \mathrm{Tu}_{60} \mathrm{~F}$ value represents the actual quality to which water is treated with respect to turbidity by the treatment processes applied. The $\mathrm{Me}_{60} \mathrm{~F}$ value represents the overall capability of the treatment process with respect to the formation of separable suspension.

The $\mathrm{COD}_{\mathrm{Mn} 60}$ value expresses the total concentration of organic matter remaining in the treated water. It is measured in a sample of treated water taken after $1 \mathrm{~h}$ sedimentation. The $\mathrm{COD}_{\mathrm{Mn} 60}$ value indicates the quality to which water is treatable with respect to organic pollution.

The $\varphi_{\mathrm{COD}}$ expresses the separation efficiency of the treatment process with respect to organic pollution. It is a ratio of the content of organic pollution separated in the treatment process and its total initial content in the raw water. It is used for comparison of the treatment efficiency achieved by individual reagents.

An important part in evaluating the treatment process efficiency of individual coagulants from an operational point of view is their coagulant dosage cost. Because the water could not be treated to the same quality by all coagulants tested, the coagulant dosage cost was established for the operational dosage $\mathrm{D}_{\mathrm{O}}$ at which the most effective reduction of all pollution determinants used was achieved. The dosage cost was calculated by multiplying the operational dosage by the coagulant price. It should be emphasised that when comparing the coagulant dosage costs, it is necessary to also take into consideration the quality of water and the quality to which it is treatable by the coagulant.

The optimum dosage means the dosage by which maximum 
reduction in the content of a pollution determinant monitored, is achieved. The operational dosage means the dosage at which the maximum possible removal of all types of impurities is achieved.

The investigation into the treatability of surface waters carried out during 1993 showed that most of the surface waters in South Africa are easily treatable to a high quality under optimum reaction conditions by the common treatment processes utilising hydrolysing reagents (Polasek and Mutl, 1995a; Polasek and Mutl, 1995b; Mutl and Polasek, 1996; Polasek and Mutl, 1997; Polasek and Mutl, 1999). These wholesome water quality limits to which the treatability of water attainable by the coagulants tested are compared, are as follows:

- cation of added hydrolysing reagent used $\mathrm{Me}=0.15 \mathrm{mg} \cdot \ell^{-1}$ and in many cases $\mathrm{Me}<0.05 \mathrm{mg} \cdot \ell^{-1}$,

- organic matter characterised by $\mathrm{COD}_{\mathrm{Mn}}=2.0 \mathrm{mg} \mathrm{O}_{2} \cdot \ell^{-1}$,

- mineral suspensions producing turbidity $\mathrm{Tu}=0.3 \mathrm{NTU}$.

When evaluating the potential of any CPE as a suitable substitute for hydrolysing reagents, the quality to which the water is treatable by CPE should be within the above limits. The reason for setting these limits, rather than referring to the limits specified in South African standard stated below, is that the range of the maximum limits allowed for in the SABS 241/99 for the respective pollution determinants are far too lax for a wholesome quality drinking water:

- cation of added hydrolysing reagent used $\mathrm{Me}=0.15$ to $0.5 \mathrm{mg}$ $\mathrm{Al} \cdot \ell^{-1}$ and $\mathrm{Me}=0.1$ to $2.0 \mathrm{mg} \mathrm{Fe} \cdot \ell^{-1}$,

- organic pollution characterized by DOC $=5$ to $20 \mathrm{mg} \mathrm{C} \cdot \ell^{-1}$ and $\mathrm{TOH}_{\mathrm{T}}=100$ to $300 \mu \mathrm{g} \mathrm{CHCl} \cdot \ell^{-1}$,

- turbidity $\mathrm{Tu}=1$ to $10 \mathrm{NTU}$.

The term "water treatment" is used in this article in the commonly accepted context of "water purification".

\section{Hydrolysing reagents}

The treatability of the water attainable by hydrolysing reagents namely, $\mathrm{FeCl}_{3}, \mathrm{Al}_{2}\left(\mathrm{SO}_{4}\right)_{3}$ and $\mathrm{PACl}(\mathrm{M}-30, \mathrm{~K}-288)$, is shown in Figures 1 to 4 . These Figures illustrate the dependence of changes of the pollution determinants on dosage. The treated water qualities obtained are summarised in Table 3.

\section{Ferric chloride}

The range of ferric chloride dosages applied was designed to almost deplete alkalinity of the water by hydrolysis. The dosages applied covered a range $\mathrm{D}=6$ to $135 \mathrm{mg} \cdot \ell^{-1}$. The results obtained are plotted in Fig. 1.

As can be seen from Fig. 1, the residual content of Fe is very low over the full range of dosages applied. The lowest residual Fe value, $\mathrm{Me}_{60} \mathrm{~F}=0.01 \mathrm{mg} \mathrm{Fe} \cdot \ell^{-1}$, was obtained at a dosage $\mathrm{D}=74 \mathrm{mg} \cdot \ell^{-1}$. Turbidity dropped rapidly up to breakpoint at a dosage $\mathrm{D}=50$ $\mathrm{mg} \cdot \ell^{-1}$ and, thereafter, gradually decreased at a much lower rate. The lowest residual turbidity, $\mathrm{Tu}_{60} \mathrm{~F}=0.12 \mathrm{NTU}$, was obtained at a dosage $\mathrm{D}=123 \mathrm{mg} \cdot \ell^{-1}$. This dosage can be considered to be the optimum dosage for destabilisation of turbidity particles. Sufficient aggregation efficiency of turbidity particles was achieved at a dosage $\mathrm{D}=65 \mathrm{mg} \cdot \ell^{-1}$. The $\mathrm{COD}_{\mathrm{Mn}}$ value decreased over the full range of dosages applied. It dropped fairly rapidly to breakpoint at a dosage $\mathrm{D}=110 \mathrm{mg} \cdot \ell^{-1}$ and, thereafter, its drop was considerably smaller. The lowest $\mathrm{COD}_{\mathrm{Mn} 60}=1.19 \mathrm{mg} \mathrm{O}_{2} \cdot \ell^{-1}$ was obtained at the

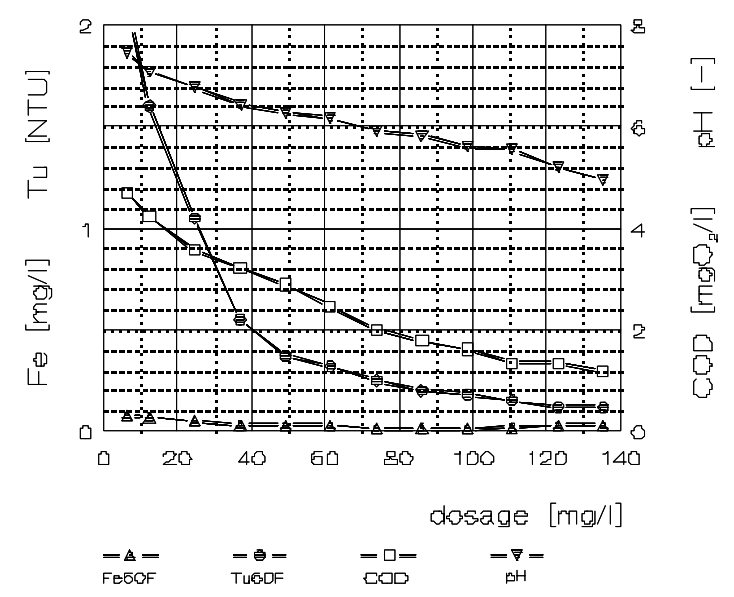

Figure 1

Treatment process efficiency attainable with $\mathrm{FeCl}_{3}$

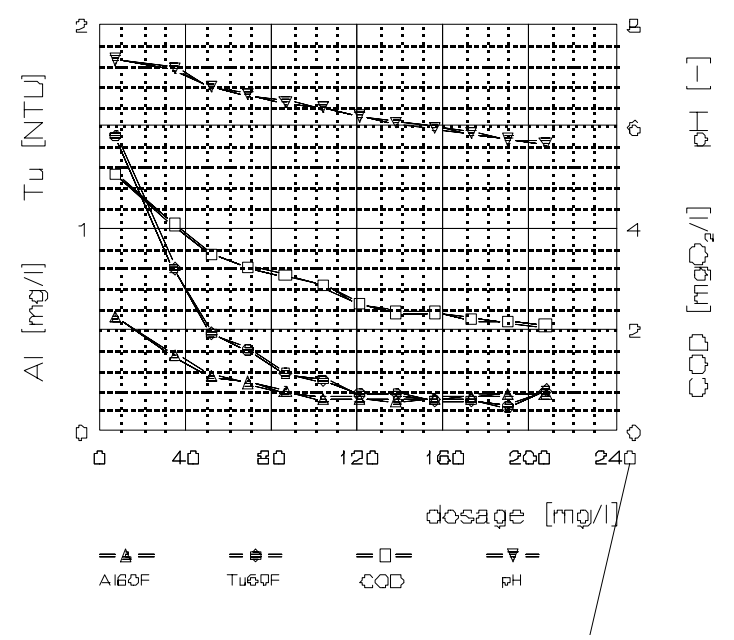

Figure 2

Treatment process efficiency attainable with $\mathrm{Al}_{2}\left(\mathrm{SO}_{4}\right)_{3}$

maximum dosage applied, $\mathrm{D}=136 \mathrm{mg} \cdot \ell^{-1}$. The reaction $\mathrm{pH}$ value dropped gradually with dosage from $\mathrm{pH}=7.46$ to 4.96 at the maximum dosage.

Based on the evaluation of the results obtained with respect to all three pollution determinants, a dosage $\mathrm{D}=75 \mathrm{mg} \cdot \ell^{-1}$ is considered to be the optimum operational dosage at which wholesome quality water is produced; the reaction $\mathrm{pH}=6.0$.

\section{Aluminium sulphate}

Due to high alkalinity and concentration of organic matter, aluminium sulphate was tested over a wide range of dosage, $\mathrm{D}=7$ to $207 \mathrm{mg} \cdot \ell^{-1}$. The results obtained are plotted in Fig. 2.

Figure 2 shows that the residual content of Al decreases rapidly up to a dosage $\mathrm{D}=86 \mathrm{mg} \cdot \ell^{-1}$ and, thereafter, decreased at a gradually diminishing rate up to a dosage $\mathrm{D}=140 \mathrm{mg} \cdot \ell^{-1}$. At higher dosages it remained almost unchanged. The lowest residual $\mathrm{Al}$ value, $\mathrm{Me}_{60} \mathrm{~F}$ $=0.15 \mathrm{mg} \mathrm{Al} \cdot \ell^{-1}$, was obtained at a dosage $\mathrm{D}=138 \mathrm{mg} \cdot \ell^{-1}$. Therefore, this dosage can be considered to be the optimum dosage of the treatment process with respect to the formation of separable suspensions. Turbidity dropped rapidly up to breakpoint at a dosage $\mathrm{D}=50 \mathrm{mg} \cdot \ell^{-1}$ and, thereafter, dropped at a much lower rate. The lowest residual turbidity, $\mathrm{Tu}_{60} \mathrm{~F}=0.12 \mathrm{NTU}$, was obtained at a dosage $\mathrm{D}=190 \mathrm{mg} \cdot \ell^{-1}$. Therefore, this dosage is considered to be 


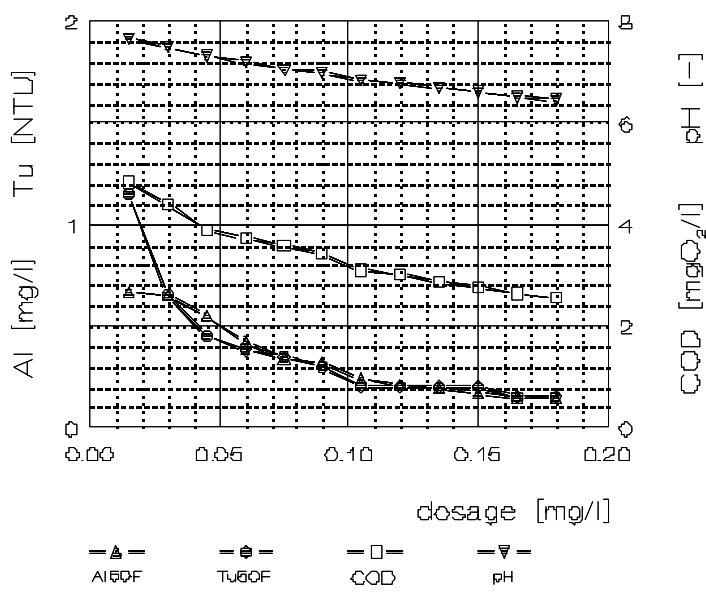

Figure 3

Treatment process efficiency attainable with PACI. Product M-30.

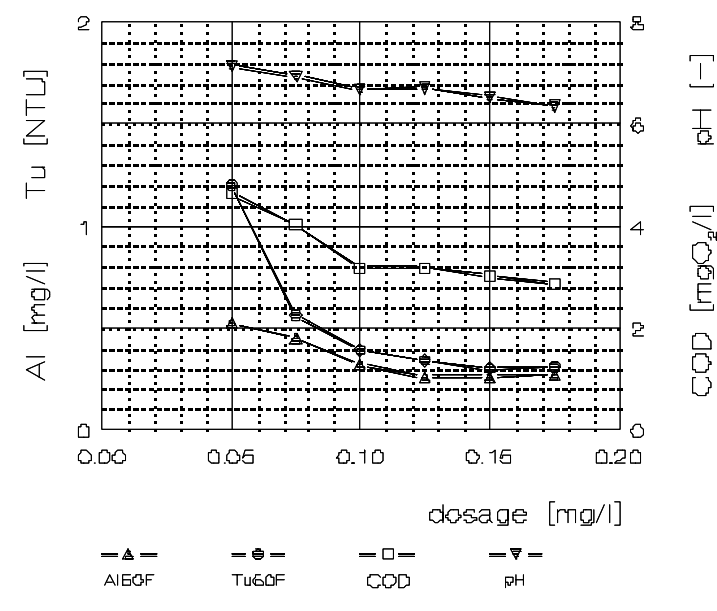

Figure 4

Treatment process efficiency attainable with PACl. Product K-288.

the optimum dosage for destabilisation of turbidity particles. Sufficient aggregation efficiency of turbidity particles was achieved at a dosage $\mathrm{D}=86 \mathrm{mg} \cdot \ell^{-1}$. The $\mathrm{COD}_{\mathrm{Mn}}$ value continuously decreased over the full range of dosages tested. From a dosage $\mathrm{D}=138 \mathrm{mg} \cdot \ell^{-1}$ the rate of decrease in $\mathrm{COD}_{\mathrm{Mn}}$ value is reduced considerably. The lowest $\mathrm{COD}_{\mathrm{Mn} 60}=2.08 \mathrm{mg} \mathrm{O}_{2} \cdot \ell^{-1}$ was obtained at the maximum dosage applied, $\mathrm{D}=207 \mathrm{mg} \cdot \ell^{-1}$. The reaction $\mathrm{pH}$ value dropped gradually with dosage from $\mathrm{pH}=7.32$ to 5.67 at the maximum dosage.

Based on the evaluation of the results obtained with respect to all three pollution determinants, a dosage $\mathrm{D}=38 \mathrm{mg} \cdot \ell^{-1}$ is considered to be the operational dosage; the reaction $\mathrm{pH}=6.2$. Wholesome quality water was not produced due to slightly higher $\mathrm{COD}_{\mathrm{Mn}}$ value.

\section{Polyaluminium chloride}

Two PACl products, namely M-30 and K-288, produced by two different manufacturers, were tested. The range of $\mathrm{PACl}$ dosages tested was designed to correspond to the range of $\mathrm{Al}$ concentration applied with aluminium sulphate. The results obtained are plotted in Figs. 3 and 4.

\section{M-30}

Figure 3 shows that the residual $\mathrm{Al}$ content gradually decreased over the full range of dosage applied. The lowest residual $\mathrm{Al}$ value, $\mathrm{Me}_{60} \mathrm{~F}=0.14 \mathrm{mg} \mathrm{Al} \cdot \ell^{-1}$, was obtained at a dosage $\mathrm{D}=0.180 \mathrm{~m} \ell \cdot \ell^{-1}$. This dosage can be considered to be the optimum dosage of the treatment process with respect to the formation of separable suspensions. The maximum permissible concentration of residual $\mathrm{Al}\left(\mathrm{Me}_{60} \mathrm{~F} \quad 0.15 \mathrm{mg} \mathrm{Al} \cdot \ell^{-1}\right)$ was obtained at a dosage $\mathrm{D}=0.165$ $\mathrm{m} \ell \cdot \ell^{-1}$. Turbidity dropped rapidly up to breakpoint at a dosage $\mathrm{D}=0.045 \mathrm{~m} \ell \cdot \ell^{-1}$ and, thereafter, dropped at a much lower rate. The lowest residual turbidity, $\mathrm{Tu}_{60} \mathrm{~F}=0.15 \mathrm{NTU}$, as obtained at a dosage $\mathrm{D}=0.165 \mathrm{~m} \ell \cdot \ell^{-1}$. Therefore, this dosage can be considered to be the optimum dosage for destabilisation of turbidity particles. Sufficient aggregation efficiency of turbidity particles was achieved at a dosage $\mathrm{D}=0.090 \mathrm{~m} \ell \cdot \ell^{-1}$. The $\mathrm{COD}_{\mathrm{Mn}}$ value gradually decreased over the full range of dosages tested. The lowest residual $\mathrm{COD}_{\mathrm{Mn} 60}$ $=2.55 \mathrm{mg} \mathrm{O} \ell_{2} \ell^{-1}$ was obtained at the maximum dosage applied, $\mathrm{D}=0.180 \mathrm{~m} \ell \cdot \ell^{-1}$. The reaction $\mathrm{pH}$ value dropped gradually with dosage from $\mathrm{pH}=7.67$ to 6.45 at the maximum dosage.

Based on the evaluation of the results obtained with respect to all three pollution determinants, a dosage $D=0.165 \mathrm{~m} \ell \cdot \ell^{-1}$ is considered to be the operational dosage; the reaction $\mathrm{pH}=6.5$. Wholesome quality water was not produced due to higher $\mathrm{COD}_{\mathrm{Mn}}$ value.

\section{$K-288$}

Figure 4 shows that the residual content of Al gradually decreased up to a dosage $\mathrm{D}=0.125 \mathrm{~m} \ell \cdot \ell^{-1}$ and thereafter remained almost unchanged. The lowest residual $\mathrm{Al}$ value, $\mathrm{Me}_{60} \mathrm{~F}=0.26 \mathrm{mg} \mathrm{Al} \cdot \ell^{-1}$, was obtained at this dosage, which is considerably higher than the maximum permissible concentration $\mathrm{Me}_{60} \mathrm{~F} 0.15 \mathrm{mg} \mathrm{Al} \cdot \ell^{-1}$. Turbidity dropped rapidly up to breakpoint at a dosage $\mathrm{D}=0.100 \mathrm{~m} \ell \cdot \ell^{-1}$ and, thereafter, gradually decreased at a diminishing rate up to a dosage $\mathrm{D}=0.150 \mathrm{~m} \ell \cdot \ell^{-1}$. At higher dosages residual turbidity remained almost unchanged. The lowest residual turbidity, $\mathrm{Tu}_{60} \mathrm{~F}=$ $0.30 \mathrm{NTU}$, was obtained at a dosage $\mathrm{D}=0.150 \mathrm{~m} \ell \cdot \ell^{-1}$. Therefore, this dosage is considered to be the optimum dosage for destabilisation of turbidity particles. The $\mathrm{COD}_{\mathrm{Mn}}$ value decreased more rapidly up to breakpoint at a dosage $\mathrm{D}=0.100 \mathrm{~m} \ell \cdot \ell^{-1}$ and, thereafter, decreased at a much lower rate. The lowest residual turbidity, $\mathrm{COD}_{\mathrm{Mn} 60}=2.85 \mathrm{mg} \mathrm{O}_{2} \cdot \ell^{-1}$, was obtained at the maximum dosage applied, $\mathrm{D}=0.175 \mathrm{~m} \ell \cdot \ell^{-1}$. The reaction $\mathrm{pH}$ value dropped gradually with dosage from $\mathrm{pH}=7.15$ to 6.35 at the maximum dosage.

Based on the evaluation of the results obtained with respect to all three pollution determinants, a dosage $D=0.150 \mathrm{~m} \ell \cdot \ell^{-1}$ is considered to be the operational dosage; the reaction $\mathrm{pH}=6.5$. Wholesome quality water was not produced due to higher $\mathrm{COD}_{\mathrm{Mn}}$ value.

\section{Pure CPE}

The following CPE of synthetic and natural origin produced by different manufacturers were tested:

(a) Synthetic: polyDADMAC:

- L-100: concentration about $20 \%$,

- M-20: concentration about 20\%,

Polyamine

- M-500: concentration about 50\%,

- Anikem 8100: concentration about 50\%.

(b) Natural: Wattle tannin based:

- Belfloc - a blend of Floccotan and polyDADMAC, their assumed ratio is 8:2. Although a blended product, Belfloc is included among the pure CPE because it is a blend of pure organic polymers. 


\begin{tabular}{|c|c|c|c|c|c|c|c|c|c|c|}
\hline \multicolumn{11}{|c|}{$\begin{array}{l}\text { TABLE } 3 \\
\text { Comparison of treated water quality attainable by the operational dosages of the different coagulants } \\
\text { tested at Saulspoort Waterworks } \\
\left(\mathrm{Tu}^{\mathrm{RW}}=55-75 \mathrm{NTU}, \mathrm{Me}^{\mathrm{RW}}=0.81 \mathrm{mg} \mathrm{Fe} \cdot \ell^{-1}, \mathrm{COD}_{\mathrm{MnRW}}=5.9-6.40 \mathrm{mg} \mathrm{O}_{2} \cdot \ell^{-1}, \mathrm{pH}^{\mathrm{RW}}=7.43-7.94, \mathrm{t}^{\mathrm{RW}}=14.7 \text { to } 16^{\circ} \mathrm{C}\right)\end{array}$} \\
\hline \multirow[t]{2}{*}{ Coagulant } & \multicolumn{3}{|c|}{$\begin{array}{l}\text { The best attainable } \\
\text { treatability of water with } \\
\text { respect to individual } \\
\text { determinantsby optimum } \\
\text { dosages } D_{0}\end{array}$} & \multicolumn{7}{|c|}{$\begin{array}{l}\text { Treatability of water with respect to all determinants } \\
\text { monitored attainable by applicable coagulant } \\
\text { dosage } D_{A} \text { and dosage cost indication }\end{array}$} \\
\hline & $\begin{array}{c}\mathrm{Me} \\
{\left[\mathrm{mg} \cdot \ell^{-1}\right]}\end{array}$ & $\begin{array}{c}\operatorname{COD}_{\mathrm{Mn}} \\
{\left[\mathrm{mg} \mathrm{O}_{2} \cdot \ell^{-1}\right]}\end{array}$ & $\begin{array}{c}\text { Tu } \\
\text { [NTU] }\end{array}$ & $\begin{array}{c}\mathrm{D}_{\mathrm{A}} \\
{\left[\mathrm{mg} \cdot \ell^{-1}\right]}\end{array}$ & $\begin{array}{c}\mathrm{Me} \\
{\left[\mathrm{mg} \cdot \ell^{-1}\right]}\end{array}$ & $\begin{array}{c}\mathrm{COD}_{\mathrm{Mn}} \\
{\left[\mathrm{mg} \mathrm{O}_{2} \cdot \ell^{-1}\right]}\end{array}$ & $\begin{array}{c}\text { Tu } \\
\text { [NTU] }\end{array}$ & $\begin{array}{c}\mathrm{pH} \\
{[-]}\end{array}$ & $\begin{array}{c}\varphi \operatorname{COD}_{\mathrm{Mn}} \\
{[-]}\end{array}$ & $\begin{array}{c}\text { Dosage } \\
\text { cost } \\
\text { factor }\end{array}$ \\
\hline \multicolumn{11}{|c|}{ Hydrolysing coagulants } \\
\hline $\mathrm{FeCl}_{3}$ & 0.01 & 1.19 & 0.12 & 75 & 0.01 & 1.99 & 0.25 & 5.92 & 0.66 & 9855 \\
\hline $\mathrm{Al}_{2}\left(\mathrm{SO}_{4}\right)_{3}$ & 0.15 & 2.08 & 0.12 & 138 & 0.15 & 2.33 & 0.18 & 6.07 & 0.61 & 12378 \\
\hline \multicolumn{11}{|c|}{$\left[\mathrm{m} \ell \cdot \ell^{-1}\right]$} \\
\hline $\begin{array}{l}\text { M-30 } \\
\text { K-288 }\end{array}$ & $\begin{array}{c}0.14 \\
-\end{array}$ & $\begin{array}{l}2.55 \\
2.85\end{array}$ & $\begin{array}{l}0.15 \\
0.30\end{array}$ & $\begin{array}{l}0.165 \\
0.150\end{array}$ & $\begin{array}{l}0.15 \\
0.25\end{array}$ & $\begin{array}{l}2.64 \\
3.02\end{array}$ & $\begin{array}{l}0.15 \\
0.30\end{array}$ & $\begin{array}{l}6.51 \\
6.52\end{array}$ & $\begin{array}{l}0.55 \\
0.50\end{array}$ & $\begin{array}{c}17020 \\
-\end{array}$ \\
\hline \multicolumn{11}{|l|}{ Pure CPE } \\
\hline $\begin{array}{l}\text { L-100 } \\
\text { M-20 } \\
\text { M-500 } \\
\text { ANIKEM } 8100 \\
\text { BELFLOC }\end{array}$ & $\begin{array}{l}\text { N/A } \\
\text { N/A } \\
\text { N/A } \\
\text { N/A } \\
\text { N/A }\end{array}$ & $\begin{array}{l}4.96 \\
4.64 \\
4.37 \\
4.80 \\
5.52\end{array}$ & $\begin{array}{l}1.15 \\
0.29 \\
0.77 \\
1.05 \\
0.26\end{array}$ & $\begin{array}{l}0.002 \\
0.006 \\
0.004 \\
0.004 \\
0.001 \\
0.006\end{array}$ & $\begin{array}{l}\text { N/A } \\
\text { N/A } \\
\text { N/A } \\
\text { N/A } \\
\text { N/A } \\
\text { N/A }\end{array}$ & $\begin{array}{l}4.96 \\
4.72 \\
4.46 \\
5.08 \\
5.52 \\
6.72\end{array}$ & $\begin{array}{l}1.90 \\
0.32 \\
1.30 \\
1.60 \\
1.20 \\
0.26\end{array}$ & $\begin{array}{l}7.78 \\
7.62 \\
7.62 \\
7.88 \\
7.83 \\
7.69\end{array}$ & $\begin{array}{c}0.21 \\
0.24 \\
0.30 \\
0.21 \\
0.12 \\
-0.08\end{array}$ & $\begin{array}{c}1163 \\
3526 \\
3068 \\
6905 \\
- \\
-\end{array}$ \\
\hline \multicolumn{11}{|l|}{ Blended CPE } \\
\hline M-101 & 0 & 3.84 & 0.37 & 0.012 & 0.00 & 4.16 & 0.52 & 7.55 & 0.35 & 5925 \\
\hline M-182 & 0 & 2.42 & 0.26 & 0.010 & 0.00 & 2.62 & 0.30 & 6.14 & 0.58 & 2310 \\
\hline DP-160 & 0.12 & 3.68 & 0.54 & $\begin{array}{l}0.005 \\
0.030\end{array}$ & $\begin{array}{l}0.12 \\
0.35\end{array}$ & $\begin{array}{l}4.48 \\
3.68\end{array}$ & $\begin{array}{l}1.80 \\
0.54\end{array}$ & $\begin{array}{l}7.44 \\
7.24\end{array}$ & $\begin{array}{l}0.26 \\
0.39\end{array}$ & $\begin{array}{c}2357 \\
14145\end{array}$ \\
\hline ANIKEM 4141 & 0.22 & 3.52 & 0.48 & $\begin{array}{l}0.005 \\
0.030\end{array}$ & $\begin{array}{l}0.22 \\
0.38\end{array}$ & $\begin{array}{l}4.69 \\
3.52\end{array}$ & $\begin{array}{l}1.95 \\
0.48\end{array}$ & $\begin{array}{l}7.43 \\
7.19\end{array}$ & $\begin{array}{l}0.22 \\
0.42\end{array}$ & $\begin{array}{c}7085 \\
42506\end{array}$ \\
\hline
\end{tabular}

The treatability of water attainable with $\mathrm{CPE}$ was tested over a wide range of dosages. The dosages are expressed in $\mathrm{m} \cdot \ell^{-1}$ of the commercially supplied stock CPE solution. The treatability of water was evaluated only by two pollution determinants $\mathrm{Tu}_{60} \mathrm{~F}$ and $\mathrm{COD}_{\mathrm{Mn} 60}$ because evaluation by residual Me is not applicable with pure organic polymers.

Treatability of the water attainable with CPE is shown in Figs. 5 to 9 . These Figures illustrate the dependence of changes of the pollution determinants $\left(\mathrm{Tu}\right.$ and $\left.\mathrm{COD}_{\mathrm{Mn}}\right)$ on dosage. The treated water quality obtained by the operational dosage of the individual reagents is shown in Table 3.

\section{Synthetic CPE}

\section{PolyDADMAC}

\section{$L-100$}

Figure 5 shows that turbidity dropped rapidly up to a dosage $\mathrm{D}=0.002 \mathrm{~m} \ell \cdot \ell^{-1}$ and, thereafter, it slowed. The lowest residual

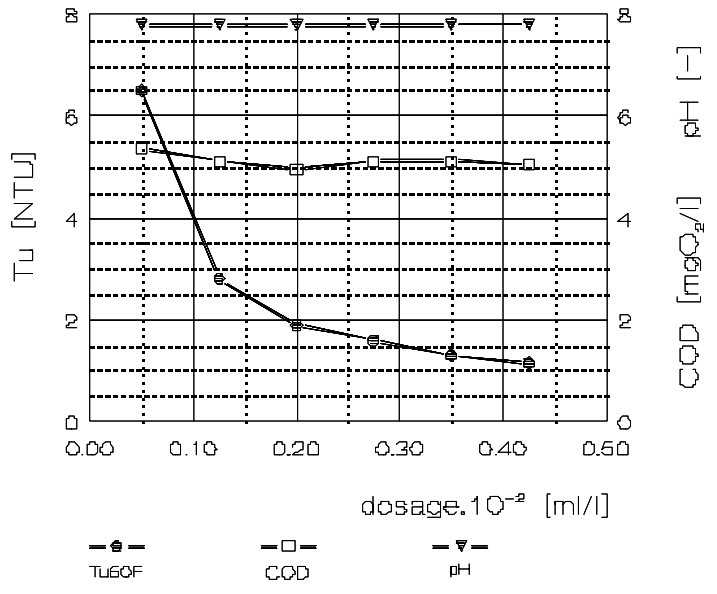

Figure 5

Treatment process efficiency attainable with PACI. Product L-100. 


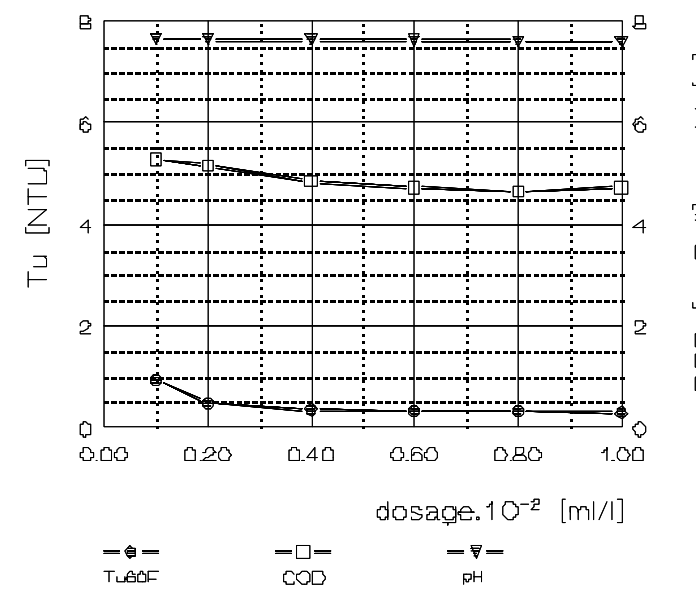

Figure 6

Treatment process efficiency attainable with CPE. Product M-20.

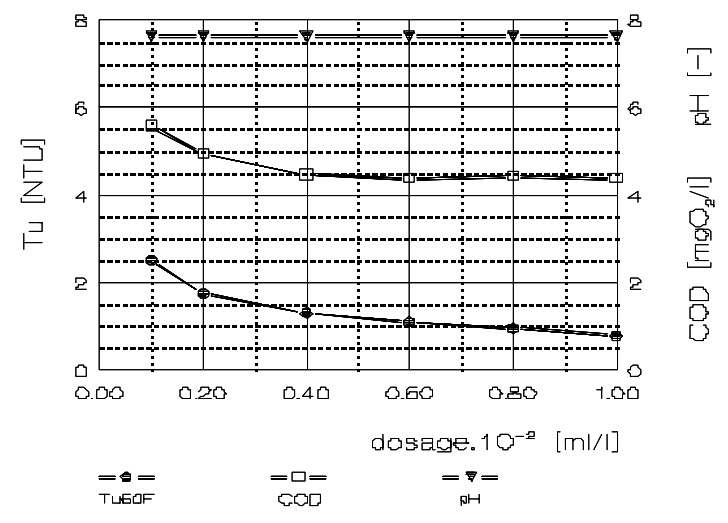

Figure 7

Treatment process efficiency attainable with CPE. Product M-500.

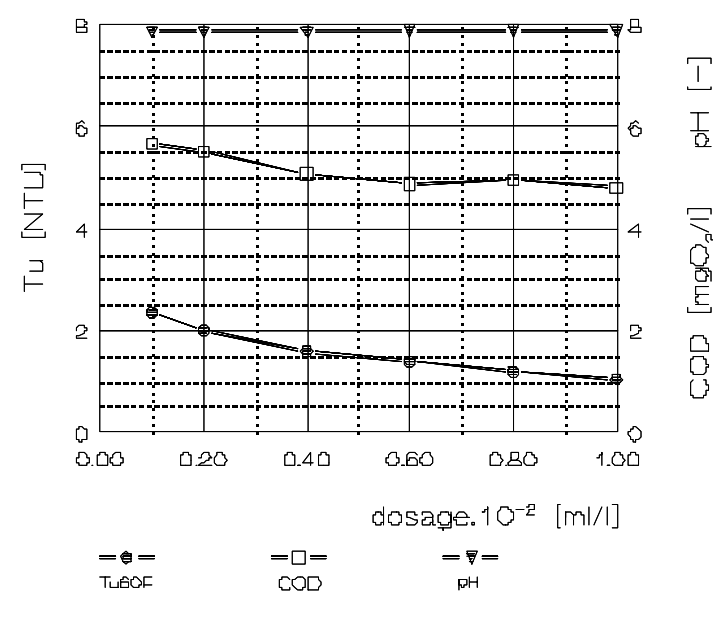

Figure 8

Treatment process efficiency attainable with CPE. Product ANIKEM 8100. turbidity, $\mathrm{Tu}_{60} \mathrm{~F}=1.15 \mathrm{NTU}$, was obtained at the maximum dosage applied, $\mathrm{D}=0.00425 \mathrm{~m} \ell \cdot \ell^{-1}$. This dosage can be considered to be the optimum dosage for aggregation of turbidity particles. The $\mathrm{COD}_{\mathrm{Mn}}$ value also decreased very slowly to up to breakpoint at a dosage $\mathrm{D}=0.002 \mathrm{~m} \ell \cdot \ell^{-1}$ and, thereafter, remained almost unchanged around $\mathrm{COD}_{\mathrm{Mn} 60}=5.10 \mathrm{mg} \mathrm{O}_{2} \cdot \ell^{-1}$. The reaction $\mathrm{pH}$ value remained stable around 7.93 over the full range of dosages applied.

An acceptable quality treated water could not be produced with any dosage applied.

\section{M-20}

Figure 6 shows that turbidity drops rapidly up to a dosage $\mathrm{D}=0.002$ $\mathrm{m} \ell \cdot \ell^{-1}$. Thereafter, it gradually diminished and from a dosage $\mathrm{D}=0.004 \mathrm{~m} \ell \cdot \ell^{-1}$ residual turbidity remained almost unchanged. The lowest residual turbidity, $\mathrm{Tu}_{60} \mathrm{~F}=0.29 \mathrm{NTU}$, was obtained at the maximum dosage applied, $\mathrm{D}=0.010 \mathrm{~m} \ell \cdot \ell^{-1}$. This dosage can be considered to be the optimum dosage for aggregation of turbidity particles. The $\mathrm{COD}_{\mathrm{Mn}}$ value decreased very slowly up to breakpoint at a dosage $\mathrm{D}=0.004 \mathrm{~m} \ell \cdot \ell^{-1}$ and, thereafter, remained almost unchanged around $\mathrm{COD}_{\mathrm{Mn} 60}=4.70 \mathrm{mg} \mathrm{O}_{2} \cdot \ell^{-1}$. The reaction $\mathrm{pH}$ value dropped with dosage only marginally from $\mathrm{pH}=7.65$ to 7.60 at the maximum dosage.

An acceptable quality treated water could not be produced with any dosage applied.

\section{Polyamine CPE}

\section{M-500}

Figure 7 shows that turbidity dropped rapidly up to a dosage $\mathrm{D}=0.004 \mathrm{~m} \ell \cdot \ell^{-1}$ and thereafter it gradually decreased at a lower rate. The lowest residual turbidity, $\mathrm{Tu}_{60} \mathrm{~F}=0.77 \mathrm{NTU}$, was obtained at the maximum dosage applied, $\mathrm{D}=0.010 \mathrm{~m} \ell \ell^{-1}$. The $\mathrm{COD}_{\mathrm{Mn}}$ value decreased very slowly up to a dosage $\mathrm{D}=0.004 \mathrm{~m} \ell \cdot \ell^{-1}$ and, thereafter, remained virtually unchanged around $\mathrm{COD}_{\mathrm{Mn} 60}=4.40$ $\mathrm{mg} \mathrm{O}_{2} \ell^{-1}$. The reaction $\mathrm{pH}$ value remained stable around 7.62 over the full range of dosages applied.

An acceptable quality treated water could not be produced with any dosage applied.

\section{Anikem 8100}

Figure 8 shows that turbidity dropped over the full range of dosages applied at a slow, almost constant rate. The lowest residual turbidity, $\mathrm{Tu}_{60} \mathrm{~F}=1.05 \mathrm{NTU}$, was obtained at the highest dosage applied, $\mathrm{D}=0.010 \mathrm{~m} \ell \cdot \ell^{-1}$. The $\mathrm{COD}_{\mathrm{Mn}}$ value gradually decreased up to a dosage $\mathrm{D}=0.004 \mathrm{~m} \ell \cdot \ell^{-1}$ and, thereafter, decreased very slowly. The lowest residual $\mathrm{COD}_{\mathrm{Mn} 60}=4.80 \mathrm{mg} \mathrm{O} \cdot \ell^{-1}$ was obtained at the highest dosage applied, $\mathrm{D}=0.010 \mathrm{~m} \ell \cdot \ell^{-1}$. The reaction $\mathrm{pH}$ value remains stable around 7.87 over the full range of dosages applied.

An acceptable quality treated water could not be produced with any dosage applied.

\section{Natural CPE}

\section{Belfloc}

Figure 9 shows that turbidity dropped rapidly up to breakpoint at a dosage $\mathrm{D}=0.030 \mathrm{~m} \ell \cdot \ell^{-1}$ and, thereafter, it decreased very slowly. The lowest residual turbidity, $\mathrm{Tu}_{60} \mathrm{~F}=0.26 \mathrm{NTU}$, was obtained at a dosage $\mathrm{D}=0.060 \mathrm{mg} \cdot \ell^{-1}$. Therefore, this dosage is considered to be the optimum dosage for aggregation of turbidity particles. Sufficient aggregation efficiency of turbidity particles was achieved at a dosage $\mathrm{D}=0.050 \mathrm{~m} \ell \cdot \ell^{-1}$. In contrast to all other CPE tested, $\mathrm{COD}_{\mathrm{Mn}}$ value gradually increased over the full range of dosages applied. The lowest residual $\mathrm{COD}_{\mathrm{Mn} 60}=5.52 \mathrm{mg} \mathrm{O} \cdot_{2} \ell^{-1}$, was 
obtained at the lowest dosage applied, $\mathrm{D}=0.010 \mathrm{~m} \ell \cdot \ell^{-1}$. The highest $\mathrm{COD}_{\mathrm{Mn} 60}=6.72 \mathrm{mg} \mathrm{O} \cdot \ell^{-1}$ was obtained at the highest dosage applied, $\mathrm{D}=0.060 \mathrm{~m} \ell \cdot \ell^{-1}$, representing an increase $\mathrm{COD}_{\mathrm{Mn}}=0.48$ $\mathrm{mg} \mathrm{O}_{2} \cdot \ell^{-1}$ in comparison to that of the raw water. The $\mathrm{COD}_{\mathrm{Mn} 60}$ value of the treated water balanced that of the raw water, $\mathrm{COD}_{\mathrm{Mn}}{ }^{\mathrm{RW}}$ $=6.24 \mathrm{mg} \mathrm{O}_{2} \cdot \ell^{-1}$ at a dosage $\mathrm{D}=0.045 \mathrm{~m} \ell \cdot \ell^{-1}$. The reaction $\mathrm{pH}$ value dropped with dosage marginally only from $\mathrm{pH}=7.83$ to 7.69 at the maximum dosage applied.

An acceptable quality treated water could not be produced with any dosage applied. A typical coagulation curve for $\mathrm{COD}_{\mathrm{Mn}}$ value was not obtained. Therefore, there is no dosage that can be considered to be the operational dosage.

\section{Blended CPE}

Treatability of the water attainable with the blended CPE is shown in Figs. 10 to 13. These Figures illustrate the dependence of changes of the pollution determinants on dosage. The treated water quality obtained by the operational dosage of the individual reagents is shown in Table 3.

The following CPE were tested:

(a) Fe-based CPE

- M-101: a blend of $\mathrm{FeCl}_{3}$ and polyamine, their assumed ratio is $1: 1$,

- M-182: ablend of $\mathrm{FeCl}_{3}$ and polyamine, their assumed ratio is $9: 1$,

(b) Al-based CPE

- DP-160: a blend of PACl, polyamine and polyDADMAC, their assumed ratio is $6: 2: 2$,

- Anikem 4141: a blend of PACl and polyamine, their assumed ratio is $1: 1$.

\section{Fe-based CPE}

\section{M-101}

Figure 10 shows that $\mathrm{Fe}$ is completely removed from the water over the full range of dosages applied. Turbidity dropped rapidly up to breakpoint at a dosage $\mathrm{D}=0.004 \mathrm{~m} \ell \cdot \ell^{-1}$ and, thereafter, it decreased slowly up to the maximum dosage applied. The lowest residual turbidity, $\mathrm{Tu}_{60} \mathrm{~F}=0.37 \mathrm{NTU}$, was obtained at the maximum dosage applied $\mathrm{D}=0.024 \mathrm{~m} \ell \cdot \ell^{-1}$. The $\mathrm{COD}_{\mathrm{Mn}}$ value also dropped fairly rapidly to breakpoint at a dosage $\mathrm{D}=0.012 \mathrm{~m} \ell \cdot \ell^{-1}$ and, thereafter, it decreased very slowly up to the maximum dosage. The lowest residual $\mathrm{COD}_{\mathrm{Mn}}$ value, $\left(\mathrm{COD}_{\mathrm{Mn} 60}=3.84 \mathrm{mg} \mathrm{O}_{2} \cdot \ell^{-1}\right.$, was obtained at the maximum dosage $\mathrm{D}=0.024 \mathrm{~m} \ell \cdot \ell^{-1}$. The reaction $\mathrm{pH}$ value dropped with dosage marginally only from $\mathrm{pH}=7.83$ to 7.35 at the maximum dosage.

An acceptable quality treated water could not be produced with any dosage applied.

\section{M-182}

Figure 11 shows that $\mathrm{Fe}$ is completely removed from the water over the full range of dosages applied. Turbidity gradually dropped over the full range of dosages applied. The lowest residual turbidity, $\mathrm{Tu}_{60} \mathrm{~F}=0.26 \mathrm{NTU}$, was obtained at the maximum dosage applied $\mathrm{D}=0.148 \mathrm{~m} \ell \cdot \ell^{-1}$. This dosage can be considered to be the optimum dosage for aggregation of turbidity particles. Sufficient aggregation efficiency of turbidity particles was achieved at a dosage $\mathrm{D}=$ $0.10 \mathrm{~m} \ell \cdot \ell^{-1}$. The $\operatorname{COD}_{\mathrm{Mn}}$ value also dropped fairly rapidly to breakpoint at a dosage $\mathrm{D}=0.075 \mathrm{~m} \ell \cdot \ell^{-1}$ and, thereafter, it decreased very slowly. The lowest residual $\mathrm{COD}_{\mathrm{Mn}}$ value, $\mathrm{COD}_{\mathrm{Mn} 60}=2.42$ $\mathrm{mg} \mathrm{O}_{2} \cdot \ell^{-1}$, was obtained at the maximum dosage $\mathrm{D}=0.148 \mathrm{~m} \ell \cdot \ell^{-1}$.

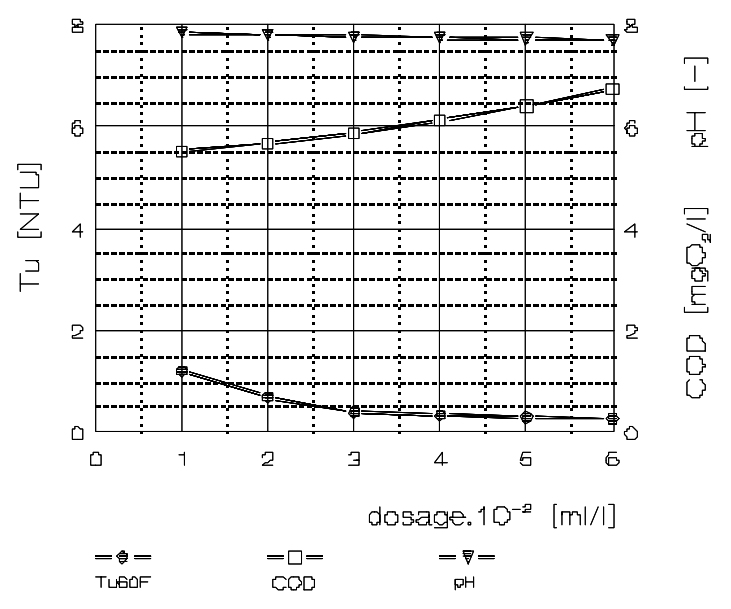

Figure 9

Treatment process efficiency attainable with CPE. Product BELFLOC.

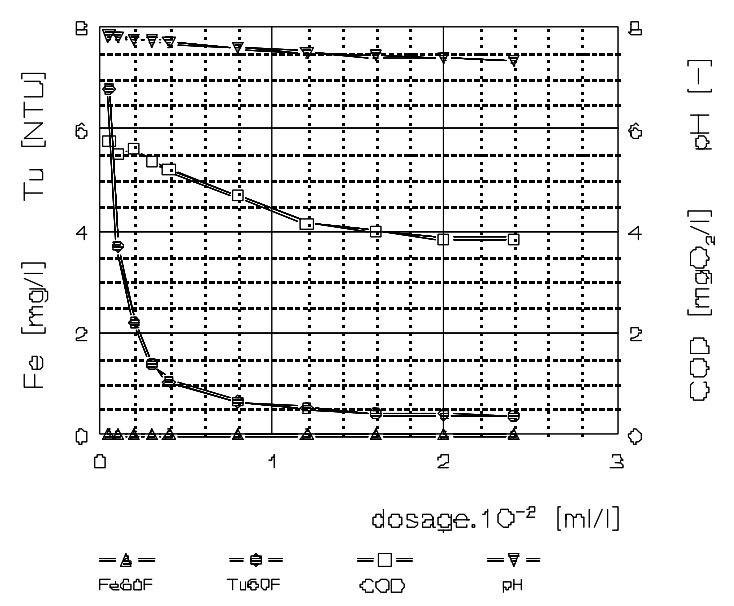

Figure 10

Treatment process efficiency attainable with CPE. Product M-101.

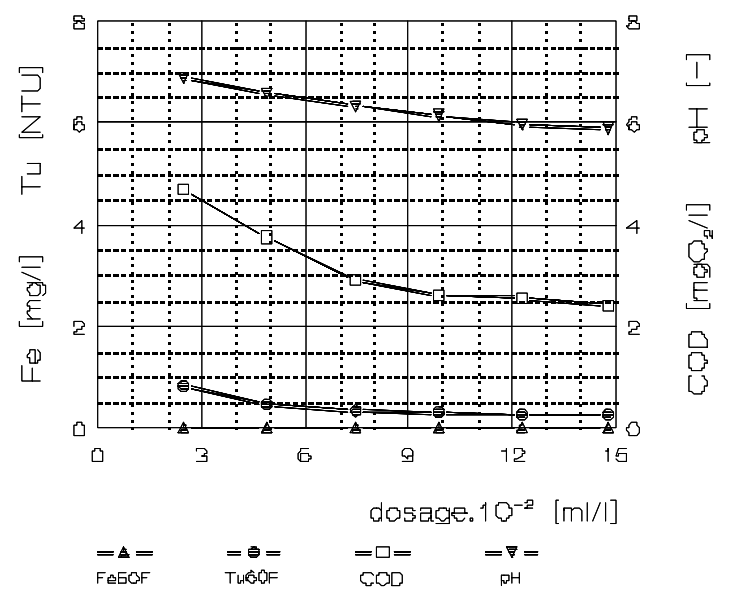

Figure 11

Treatment process efficiency attainable with CPE. Product M-182. 


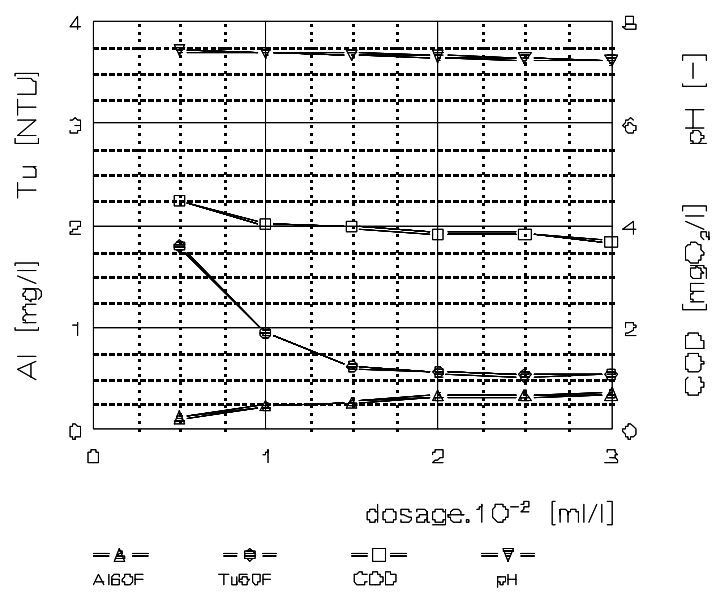

Figure 12

Treatment process efficiency attainable with CPE. Product DP-160.

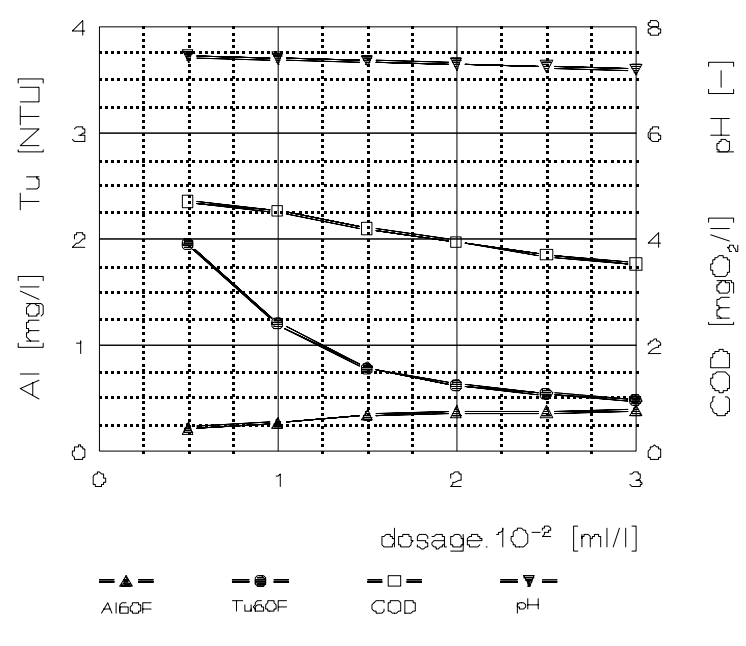

Figure 13

Treatment process efficiency attainable with CPE. Product ANIKEM 4141.

The reaction $\mathrm{pH}$ value dropped gradually with dosage from $\mathrm{pH}=$ 6.87 to 5.89 at the maximum dosage.

An acceptable quality treated water could not be produced with any dosage applied.

\section{Al-based CPE}

\section{DP-160}

Figure 12 shows that the residual $\mathrm{Al}$ content slowly increases at a gradually reducing rate from $\mathrm{Me}_{60} \mathrm{~F}=0.22 \mathrm{mg} \mathrm{Al} \cdot \ell^{-1}$ at the minimum dosage to $\mathrm{Me}_{60} \mathrm{~F}=0.38 \mathrm{mg} \mathrm{Al} \cdot \ell^{-1}$ at the maximum dosage. Turbidity dropped fairly rapidly up to breakpoint at a dosage $\mathrm{D}=0.015$ $\mathrm{m} \ell \cdot \ell^{-1}$ and, thereafter, it decreases very slowly up to a dosage $\mathrm{D}=$ $0.025 \mathrm{~m} \ell \cdot \ell^{-1}$. From this dosage onward residual turbidity remained unchanged. The lowest residual turbidity, $\mathrm{Tu}_{60} \mathrm{~F}=0.53 \mathrm{NTU}$, was obtained at a dosage $\mathrm{D}=0.025 \mathrm{~m} \ell \cdot \ell^{-1}$. The $\mathrm{COD}_{\mathrm{Mn}}$ value gradually decreased over the full range of dosages applied. The lowest $\mathrm{COD}_{\mathrm{Mn} 60}=3.68 \mathrm{mg} \mathrm{O}_{2} \ell^{-1}$ was measured at the maximum dosage, $\mathrm{D}=0.030 \mathrm{~m} \ell \cdot \ell^{-1}$. The reaction $\mathrm{pH}$ value dropped with dosage only marginally from $\mathrm{pH}=7.44$ to 7.24 at the maximum dosage.

An acceptable quality of the treated water could not be produced with any dosage applied. A typical coagulation curve for residual
Al was not obtained. Therefore, there is no dosage that can be considered to be the operational dosage.

\section{Anikem 4141}

Figure 13 shows that the residual $\mathrm{Al}$ content slowly increases at a reducing rate from $\mathrm{Me}_{60} \mathrm{~F}=0.22 \mathrm{mg} \mathrm{Al} \cdot \ell^{-1}$ at the minimum dosage to $\mathrm{Me}_{60} \mathrm{~F}=0.38 \mathrm{mg} \mathrm{Al} \cdot \ell^{-1}$ at the maximum dosage. Turbidity dropped fairly rapidly up to breakpoint at a dosage $\mathrm{D}=0.015 \mathrm{~m} \ell \cdot \ell^{-1}$ and, thereafter, its drop gradually decreased up to the maximum dosage $\mathrm{D}=0.030 \mathrm{~m} \ell \cdot \ell^{-1}$. The lowest residual turbidity, $\mathrm{Tu}_{60} \mathrm{~F}=0.48$ NTU, was obtained at the maximum dosage. The $\mathrm{COD}_{\mathrm{Mn}}$ value gradually decreased over the full range of dosages applied. The lowest $\mathrm{COD}_{\mathrm{Mn} 60}=3.52 \mathrm{mg} \mathrm{O} \cdot \ell^{-1}$ was measured at the maximum dosage, $\mathrm{D}=0.030 \mathrm{~m} \ell \cdot \ell^{-1}$. The reaction $\mathrm{pH}$ value dropped with dosage only marginally from $\mathrm{pH}=7.43$ to 7.19 at the maximum dosage.

An acceptable quality treated water could not be produced with any dosage applied. A typical coagulation curve for residual Al was not obtained. Therefore, there is no dosage that can be considered to be the operational dosage.

\section{Influence of reaction $\mathrm{pH}$ on the removal of organic matter by CPE}

It is evident from the foregoing that a considerable difference in the treatment process efficiency between CPE and hydrolysing reagent exists. It seems that this difference could be connected to reaction $\mathrm{pH}$ value. It is evident from Figs. 1 to 4 that the reaction $\mathrm{pH}$ dropped considerably when treatment is by hydrolysing reagents and that the treatment process efficiency with respect to the removal of organic matter gradually increased with decreasing $\mathrm{pH}$ value. On the contrary, Figs. 5 to 9 show the reaction $\mathrm{pH}$ value of water treated by CPE remained almost unchanged in comparison to that of the raw water and the treatment process efficiency achieved with respect to the removal of organic matter was found to be insignificant. Therefore, the influence of the reaction $\mathrm{pH}$ value on the efficiency of removing organic pollution $\left(\mathrm{COD}_{\mathrm{Mn}}\right.$ value) by $\mathrm{CPE}$ was also investigated.

The raw water was pre-treated by different dosages of $\mathrm{H}_{2} \mathrm{SO}_{4}$ prior to the addition of CPE. The tests were carried out with L-100 at a constant dosage $\mathrm{D}=0.002 \mathrm{~m} \ell \cdot \ell^{-1}$ and Belfloc at a constant dosage $\mathrm{D}=0.030 \mathrm{~m} \ell \ell^{-1}$. The results obtained are plotted in Figs. 14 and 15.Pre-acidification of the water improved removal of turbidity by both CPE. In the case of polyDADMAC L-100, residual turbidity dropped from $\mathrm{Me}_{60} \mathrm{~F}=1.80$ to $1.50 \mathrm{NTU}$ as a result of lowering the reaction $\mathrm{pH}$ value from 7.73 to 5.76. In the case of Belfloc, lowering of the reaction $\mathrm{pH}$ value from 7.45 to 5.98 resulted in reducing the $\mathrm{Me}_{60} \mathrm{~F}$ value from 0.40 to $0.31 \mathrm{NTU}$. Regarding removal of organic matter, pre-acidification of the water did not change $\mathrm{COD}_{\mathrm{Mn} 60}$ value at all in the case of polyDADMAC L-100 (Fig. 14). In the case of Belfloc, preacidification of the water caused the $\mathrm{COD}_{\mathrm{Mn} 60}$ value to drop slightly from $6.32 \mathrm{mg} \mathrm{O}_{2} \cdot \ell^{-1}$ to approximately $5.50 \mathrm{mg} \mathrm{O}_{2} \cdot \ell^{-1}$.

\section{Secondary organic pollution of water caused by CPE}

The existence of secondary organic pollution is evident from the comparison of DOC, $\mathrm{COD}_{\mathrm{Mn}}$ and $\mathrm{TOH}_{\mathrm{P}}$ values measured in the raw water and the treated water.

The potential of the CPE to cause secondary organic pollution was established at Saulspoort Waterworks during 1983, when Floccotan was used as the coagulant. Its extent is evident from the 


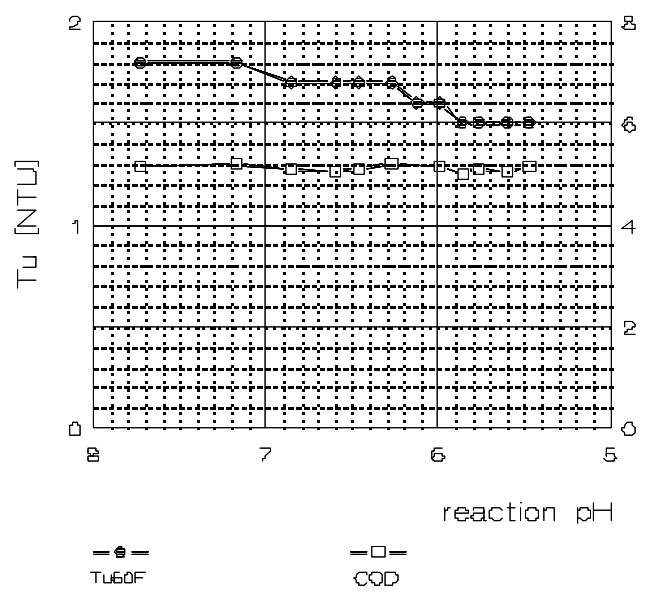

Figure 14

Influence of reaction $\mathrm{pH}$. Product $L-100 . D=0.0002 \mathrm{me} / \mathrm{l}$

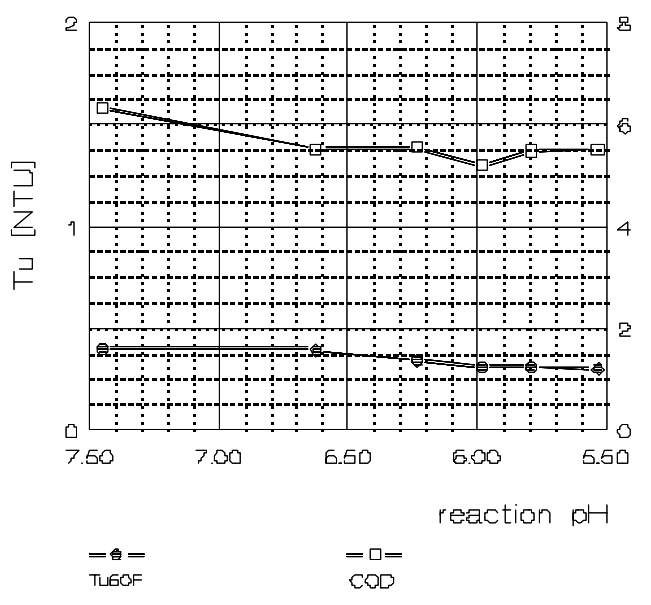

Figure 15

Influence of reaction $\mathrm{pH}$.

Product BELFLOC. $D=0.03 \mathrm{me} / \mathrm{l}$

results in Table 2. Although DOC value was reduced slightly by the treatment process, the $\mathrm{TOH}_{\mathrm{p}}$ value increased by almost $40 \%$ in comparison to that of the raw water. This indicates that while the overall organic pollution was reduced slightly, an undesirable residue of $\mathrm{CPE}$, producing considerable additional concentration of $\mathrm{TOH}$ precursors, remained in the treated water.

Another example of the existence of secondary pollution produced by CPE is evident from the tests with Belfloc, described in the foregoing and shown in Fig 9. These tests showed that when water was treated to produce the lowest residual turbidity, CPE effectively polluted the treated water to the extent that the $\mathrm{COD}_{\mathrm{Mn}}$ value of the treated water was higher than that of the raw water.

\section{Discussion of the results obtained}

The dependence of changes of the pollution determinants on dosage of the coagulants tested is shown in Figs. 1 to 13. The quality to which the raw water was treatable by their respective optimum and applicable dosages are presented in Table 3. It should be pointed out that the applicable dosage $\mathrm{D}_{\mathrm{A}}$ corresponds to the operational dosage only in case of the hydrolysing coagulants. In case of all the CPE, pure or blended, the applicable dosage $\mathrm{D}_{\mathrm{A}}$

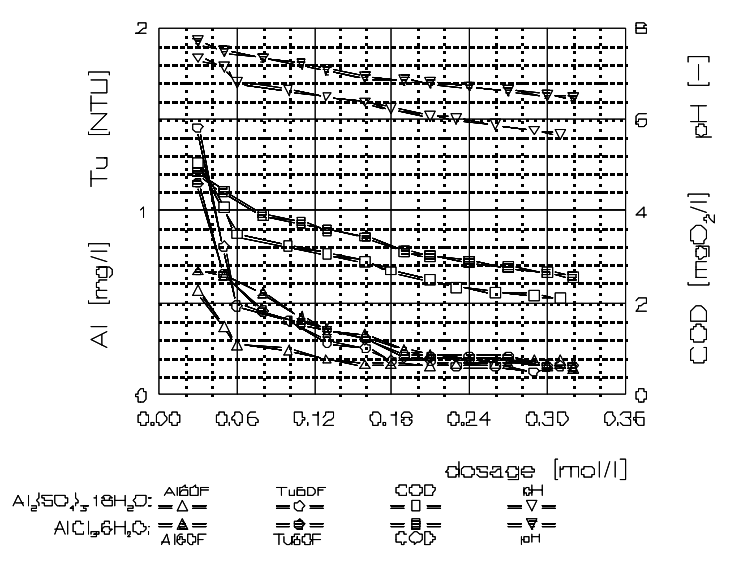

Figure 16

Comparison of treatment efficiency of $\mathrm{Al}_{2}\left(\mathrm{SO}_{4}\right)_{3}$ with $\mathrm{PACl}$

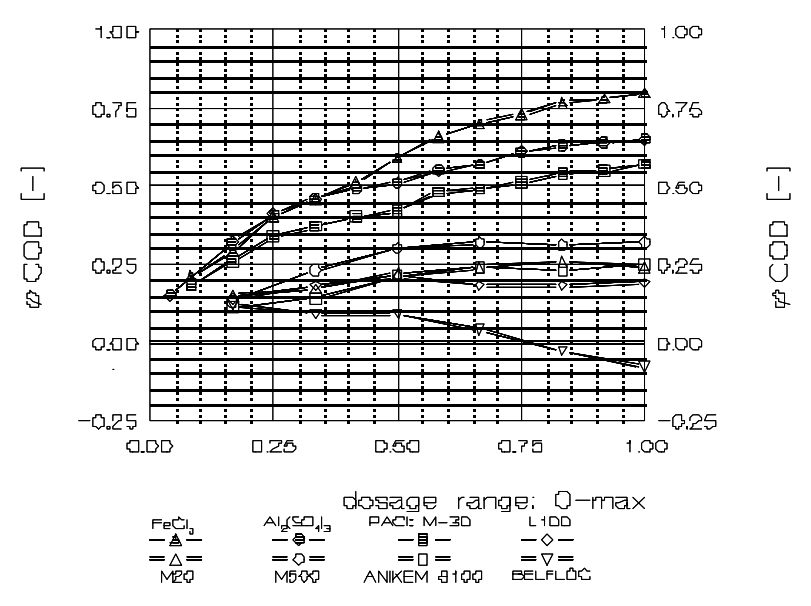

Figure 17

Comparison of sep. efficiencies of organic matter by pure coagulants

corresponds to a dosage that would be applied at the waterworks should the particular coagulant be used, irrespective of its technological suitability.

The effect of pre-acidification of the water on changes in removal of turbidity and organic matter by different CPE is shown in Figs. 14 and 15. Comparison of the treatment process efficiency obtained by the same dosages of aluminium sulphate and PACl (M30) is shown in Fig. 16. The dependence of separation efficiency of organic matter, $\varphi \mathrm{COD}_{\mathrm{Mn}}$, on dosage of all coagulants tested is compared in Figs. 17 to 19 . The separation efficiencies attainable by the CPE with that attainable by hydrolysing reagents are compared in Fig. 17. The separation efficiencies attainable by blended Fe-based CPE with that attainable by ferric chloride are compared in Fig. 18 and those attainable by blended Al-based CPE with that by aluminium sulphate and PACl are compared in Fig. 19. It should be noted that dosages indicated in Figs. 17 to 19 represent a span between 0 and maximum dosage applied, which is expressed by unit ratio.

The dependence of the treated water quality on dosage rate of different hydrolysing reagents is shown in Figs. 1 to 4 . The water was treatable to within the limits set out for wholesome quality water only with ferric chloride. Aluminium sulphate was found to be less effective. This was expected because aluminium sulphate is not particularly effective for the treatment of high alkalinity and 


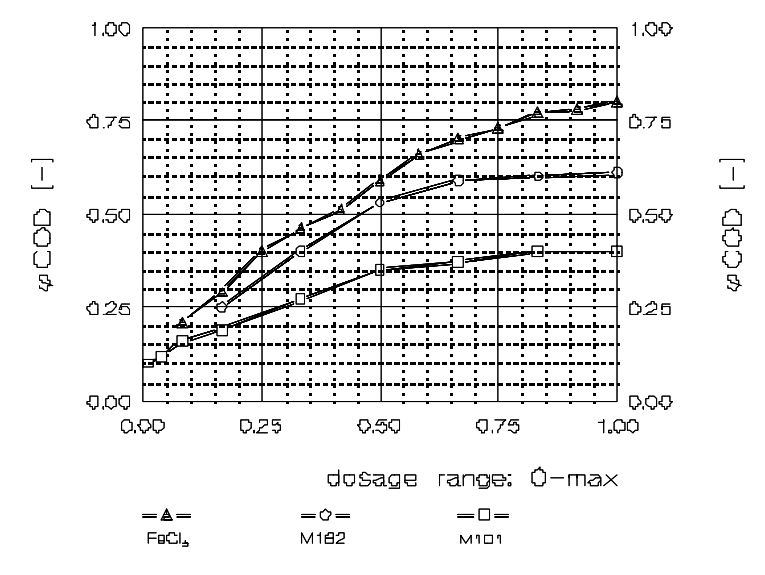

Figure 18

Comparison of sep. efficiencies of organic matter by Fe-based coagulants

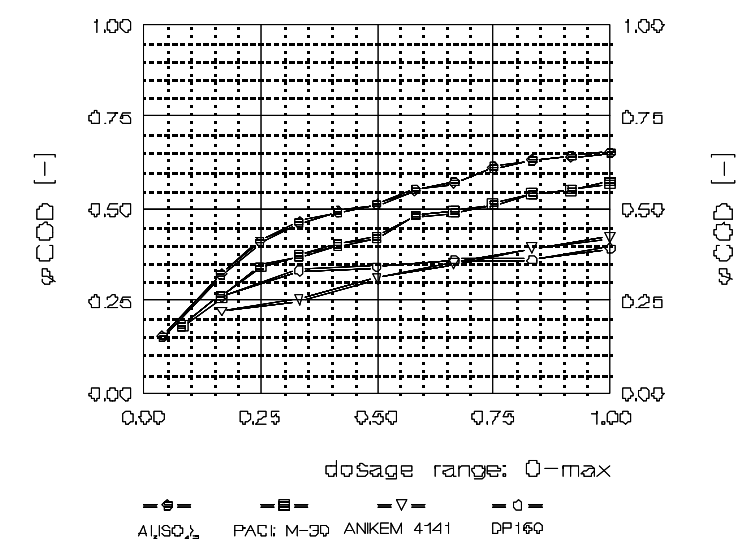

Figure 18

Comparison of sep. efficiencies of organic matter by Al-based coagulants

high ionic strength waters as is the Saulspoort Dam water. On the other hand, aluminium sulphate was found to be more effective than any of the $\mathrm{PACl}$ tested. A comparison of the treated water quality obtained with $\mathrm{PACl}$ showed that M-30 is more efficient than K-288. This is probably a result of different degrees to which $\mathrm{AlCl}_{3}$ in both $\mathrm{PACl}$ were pre-polymerised. Ferric chloride is considered to be the most suitable hydrolysing coagulant for treatment of the Saulspoort Dam water.

A comparison of $\mathrm{Tu}_{60} \mathrm{~F}, \mathrm{Me}_{60} \mathrm{~F}$ and $\mathrm{COD}_{\mathrm{Mn} 60}$ values obtained by $\mathrm{PACl}$ with those obtained by aluminium sulphate (Figs. 2 to 4 and 16) shows $\mathrm{PACl}$ to be less efficient with respect to the removal of organic matter and residual $\mathrm{Al}$, but on par with respect to the removal of turbidity. Hence, the treatment process efficiency achieved by $\mathrm{PACl}$ was found to be considerably lower than that by aluminium sulphate. The reaction $\mathrm{pH}$ value determines the form of the destabilisationly effective polymers that originate during hydrolysis, the hydroxopolymer, and the space arrangement of the chains of the organic matter. The optimum reaction $\mathrm{pH}$ at which the highest removal of organic impurities is achieved, is usually between $\mathrm{pH}=4$ to 6 .

It should be emphasised that residual Me is solubility dependent which, in turn, is reaction $\mathrm{pH}$ - dependent. In the case of aluminium sulphate, its minimum solubility is obtained at a $\mathrm{pH}$ of 4.5 and with increasing $\mathrm{pH}$ value its solubility increases. $\mathrm{PACl}$ is characterised by a lower acidity equivalent than that of aluminium sulphate.
Therefore, a much higher dosage of $\mathrm{PACl}$ is required to produce the same reaction $\mathrm{pH}$ as that produced by aluminium sulphate, as is evident from Fig. 16.

It is evident from Figs. 1 to 4 that the $\mathrm{COD}_{\mathrm{Mn}}$ value slowly decreases with dosage and its lowest value is obtained in the range of higher dosages, where $\mathrm{pH}$ value is lower and the macromolecule chains are unravelled, thus making further functional groups accessible to the particles of destabilisation reagent. For these reasons, the lowest $\mathrm{COD}_{\mathrm{Mn}}$ value is obtained at a higher dosage than that at which the lowest Me content is achieved.

The dependence of the treated water quality on dosage rate of CPE is shown in Figs. 5-9. A comparison of the results in Figs. 5 and 6 shows that neither of the polyDADMAC reagents (M-20, L100) was capable of any meaningful removal of organic matter from the water. However, M-20 was evidently capable of treating the water to sparkling clarity, while L-100 was not. With respect to the removal of organic pollution, M-20 was again marginally more efficient than L-100. The only explanation for the differences in the process efficiency between these two polyDADMAC reagents having the same solids content is that the polyDADMAC used in L-100 is of different formulation than that used in M-20.

A comparison of the results in Figs. 7 and 8 shows that neither of the polyamine reagents (M-500, Anikem 8100) was capable of any meaningful removal of organic matter from the water, although M-500 seems to be marginally more efficient than Anikem 8100 . Further, it shows that neither of these CPE was capable of treating the water to sparkling clarity, although again M-500 seems to be marginally more efficient. The only explanation for these small differences in the treatment process efficiencies is that the polyamine used in Anikem 8100 is of a different formulation than that used in M-500. Furthermore, Table 3 shows that the M-500 reagent dosage cost is considerably smaller than that of Anikem 8100.

The quantities of different types of particles of organic impurities removed by the dosage-cost cheapest hydrolysing reagent $\left(\mathrm{FeCl}_{3}\right)$ and CPE (L-100) (similar situation applies to all other CPE), are compared in Table 4 . The particles of impurities aggregated during the treatment process are those of dissolved organic impurities that are capable of specific adsorption onto the surface of the formed suspension at the reaction $\mathrm{pH}$ of the system. In comparison, the quantity of organic impurities aggregated by the treatment with $\mathrm{FeCl}_{3}$ was more than 10 times larger.

The dependence of the treated water quality on Belfloc dosage is shown in Fig. 9. As can be seen from this figure, considerable secondary organic pollution of the water occurred. This is evident by the $\mathrm{COD}_{\mathrm{Mn} 60}$ value rapidly increasing with increasing Belfloc dosage. The extent of this secondary organic pollution was such that it exceeded the quantity of organic impurities actually removed. A situation arose when the quantity of organic matter removed and that originating from treatment by the Belfloc treatment were in balance at a dosage $\mathrm{D}=0.045 \mathrm{~m} \ell \cdot \ell^{-1}$, corresponding to $\varphi \mathrm{COD}_{\mathrm{Mn}}=$ 0.0 . At higher Belfloc dosages the treated water had greater organic pollution (higher $\mathrm{COD}_{\mathrm{Mn}}$ value) than that of the raw water. Furthermore, a typical coagulation curve for $\mathrm{COD}_{\mathrm{Mn}}$ value was not obtained. Due to this, Belfloc has no dosage that can be considered to be the operational dosage and this makes Belfloc a totally undesirable reagent for the treatment of drinking water.

The dependence of the treated water quality on dosage of blended CPE is shown in Figs. 10 to 13. The blended Fe-based CPE were found to be less efficient with respect to the removal of organic impurities than ferric chloride, but considerably more efficient than the blended PACl-based CPE, which were found to be rather inefficient. In the case of Fe-based CPE, Fe was removed completely. In contrast, the residual $\mathrm{Al}$ remaining in the water 
TABLE 4

Type and quantity of particles removed by treatment with hydrolysing coagulant and CPE

\begin{tabular}{|l|c|c|c|}
\hline Type of particles & Reading & FeCl $_{3}$ & L-100 \\
\hline Total quantity of particles in the raw water & $\mathrm{COD}_{\mathrm{MnRW}}$ & 5.93 & 6.24 \\
Quantity of non-separable particles in the raw water & $\mathrm{COD}_{\mathrm{MnRW}} \mathrm{F}$ & 5.38 & 5.36 \\
Quantity of particles in a particulate, separable form in the raw water & $\Delta \mathrm{COD}_{\mathrm{MnRW}-\mathrm{P}}$ & 0.55 & 0.88 \\
\hline Total quantity of particles in the raw water & $\mathrm{COD}_{\mathrm{MnRW}}$ & 5.93 & 6.24 \\
Total quantity of particles remaining in the treated water & $\mathrm{COD}_{\mathrm{Mn} 60}$ & 1.19 & 4.96 \\
Total quantity of particles removed by treatment & $\Delta \mathrm{COD}_{\mathrm{MnTW}-\mathrm{T}}$ & 4.74 & 1.28 \\
\hline Total quantity of particles removed by treatment & $\Delta \mathrm{COD}_{\mathrm{MnTW}-\mathrm{T}}$ & 4.74 & 1.28 \\
Total quantity of particles in particulate, separable form & $\Delta \mathrm{COD}_{\mathrm{MnRW}-\mathrm{P}}$ & 0.55 & 0.88 \\
Total quantity of non-separable particles removed by treatment & $\Delta \mathrm{COD}_{\mathrm{MnTW}-\mathrm{N}}$ & 4.19 & 0.40 \\
\hline
\end{tabular}

treated by blended PACl-based CPE was higher than that obtained with treatment by aluminium sulphate. Furthermore, residual $\mathrm{Al}$ was found to increase gradually with dosage over the full range of dosages applied, well above the preset limiting concentration, $\mathrm{c}=$ $0.15 \mathrm{mg} \mathrm{Al} \cdot \ell^{-1}$. This is the result of higher reaction $\mathrm{pH}$ in comparison to that of aluminium sulphate. Furthermore, a comparison of the results obtained also shows that it is the Me component that is effective and that the treatment efficiency increases with the Me content in the CPE. The organic polymer component in the CPE is destabilisationly ineffective.

As can be seen from the results in Figs. 14 and 15, different reaction $\mathrm{pH}$ values did not affect the overall treatment process efficiency attainable by CPE of synthetic (polyDADMAC) and natural (Belfloc) origin in any meaningful way. Hence, the effect of reaction $\mathrm{pH}$ on the removal of organic matter by treatment with CPE is rather low. Consequently, the differences in separation efficiencies between hydrolysing coagulants and CPE result from their different mechanisms, enabling particle aggregation. The separation of impurities by hydrolysing coagulants includes those mechanisms for which the prerequisite for aggregation is the preceding destabilisation of the impurities, the efficiency of which is determined, to a great extent, by the type of the hydroxopolymer being formed. The predominating type of the hydroxopolymer changes with $\mathrm{pH}$ value and is most destabilisationly effective at $\mathrm{pH}=4$ to 6 . The conditions for destabilisation are determined by the chemical composition of impurities and, in particular, by the structure of organic matter, which is also $\mathrm{pH}$-dependent. These aspects determine the selection of a suitable hydrolysing coagulant, width of destabilisation optimum, operational dosage and reaction $\mathrm{pH}$ value. In contrast, CPE probably functions as destabilisation reagents only in the case of solid mineral particles. They do not cause destabilisation of organic impurities - their separation is a result of aggregation of impurities caused mainly by the mechanism of interparticle bridging and partly by the mechanism of particle enmeshment.

Separation efficiencies with respect to organic matter $\left(\mathrm{COD}_{\mathrm{Mn}}\right.$ value) achieved by pure coagulants, both hydrolysing and CPE, are compared in Fig. 17. The separation efficiencies with respect to the same determinant achieved by the blended Fe-based CPE and ferric chloride are compared in Fig. 18 and by the blended Al-based CPE are compared with aluminium sulphate and $\mathrm{PACl}$ in Fig. 19. The lowest attainable residual values of the three determinants together with their residual values attained by the operationally applicable dosages of coagulants tested are compared in Table 3.
Mutual comparison of the results in Figs. 1 to 9 and 17 shows that hydrolysing coagulants, and in particular ferric chloride, responded very effectively to the removal of all three pollution determinants and all were well below the preset limiting values, i.e. $\mathrm{COD}_{\mathrm{Mn}} \leq 2.0 \mathrm{mg} \mathrm{O} \cdot_{2} \cdot \ell^{-1}, \mathrm{Me} \leq 0.15 \mathrm{mg} \cdot \ell^{-1}$ and $\mathrm{Tu} \leq 0.15 \mathrm{NTU}$. The highest separation efficiency with respect to the removal of organic impurities was produced by ferric chloride $\varphi \mathrm{COD}_{\mathrm{Mn}}=80 \%\left(\mathrm{COD}_{\mathrm{Mn} 60}\right.$ $\left.=1.19 \mathrm{mg} \mathrm{O}_{2} \cdot \ell^{-1}\right)$. The separation efficiency attainable by aluminium sulphate was lower, $\varphi \mathrm{COD}_{\mathrm{Mn}}=65 \%\left(\mathrm{COD}_{\mathrm{Mn} 60}=2.08 \mathrm{mg} \mathrm{O}_{2} \cdot \ell^{-1}\right)$ due to the chemical composition of the water, but was on par with the desired $\mathrm{COD}_{\mathrm{Mn}}$ value. The separation efficiency attainable by $\mathrm{PACl}$ was very low and exceeded the desired $\mathrm{COD}_{\mathrm{Mn}}$ value, $\varphi \mathrm{COD}_{\mathrm{Mn}}=57 \%\left(\mathrm{COD}_{\mathrm{Mn} 60}=2.55 \mathrm{mg} \mathrm{O} \cdot_{2} \ell^{-1}\right)$. In comparison to hydrolysing reagents, the separation efficiencies of polyDADMAC and polyamine $C P E$ were found to be totally insignificant, $\varphi C O D_{M n}$ $=22$ to $32 \%\left(\mathrm{COD}_{\mathrm{Mn} 60}=4.96\right.$ to $\left.4.37 \mathrm{mg} \mathrm{O}_{2} \cdot \ell^{-1}\right)$. Neither of the $\mathrm{CPE}$ was capable of treating the water to within the above pollution determinant limits. In the case of wattle tannin extract based natural CPE, its separation efficiency decreases continuously, proportionately to dosage over the full range of dosages applied, $\varphi \mathrm{COD}_{\mathrm{Mn}}=-8$ to $14 \%\left(\mathrm{COD}_{\mathrm{Mn} 60}=6.72\right.$ to $\left.5.52 \mathrm{mg} \mathrm{O} \cdot_{2}^{-1}\right)$. The negative value means that the secondary pollution caused by this CPE was of such a magnitude that it exceeded the quantity of organic matter removed by the treatment process, making the treated water more polluted than the raw water.

Comparison of the results of the treatability of water attainable by blended Fe-based CPE with that of ferric chloride (Figs. 10, 11 and 18 and Table 3 ) shows ferric chloride to be considerably more efficient for the removal of organic matter than either of the blended Fe-based CPE, namely M-182 and M-101. The best separation efficiency was obtained with ferric chloride, $\varphi \mathrm{COD}_{\mathrm{Mn}}=80 \%$ $\left(\mathrm{COD}_{\mathrm{Mn} 60}=1.19 \mathrm{mg} \mathrm{O} \cdot_{2} \ell^{-1}\right)$. The separation efficiency obtained with M-182 ( containing about $90 \%$ ferric chloride) was $\varphi \mathrm{COD}_{\mathrm{Mn}}$ $=61 \%\left(\mathrm{COD}_{\mathrm{Mn} 60}=2.42 \mathrm{mg} \mathrm{O}_{2} \cdot \ell^{-1}\right)$. The lowest separation efficiency was obtained with M-101 (containing about $50 \%$ ferric chloride) $\varphi \mathrm{COD}_{\mathrm{Mn}}=40 \%\left(\mathrm{COD}_{\mathrm{Mn} 60}=3.84 \mathrm{mg} \mathrm{O}_{2} \cdot \ell^{-1}\right)$. Further, the separation efficiencies of M-182 or M-101 in removing Me were on par and Tu was below those obtained with ferric chloride. The differences between the separation efficiencies decreases with an increasing content of Fe-salt in the CPE.

Comparison of the results of the treatability of water attainable by blended PACl-based CPE with that by aluminium sulphate and pure $\mathrm{PACl}$ (Figs. 12, 13 and 19 and Table 3) shows aluminium sulphate to be considerably more effective overall than $\mathrm{PACl}$ and 
the blended PACl-based CPE. The best separation efficiency with respect to organic matter was obtained with aluminium sulphate, $\varphi \mathrm{COD}_{\mathrm{Mn}}=65 \%\left(\mathrm{COD}_{\mathrm{Mn} 60}=2.08 \mathrm{mg} \mathrm{O} \mathrm{O}_{2} \cdot \ell^{-1}\right)$. The separation efficiency obtained with PACl (M-30) was $\varphi \mathrm{COD}_{\mathrm{Mn}}=57 \%$ $\left(\mathrm{COD}_{\mathrm{Mn} 60}=2.55 \mathrm{mg} \mathrm{O}_{2} \cdot \ell^{-1}\right)$ only. The lowest separation efficiencies were obtained with blended PACl-based CPE: $\varphi \mathrm{COD}_{\mathrm{Mn}}=39 \%$ $\left(\mathrm{COD}_{\mathrm{Mn} 60}=3.68 \mathrm{mg} \mathrm{O}_{2} \cdot \ell^{-1}\right)$ with DP-160 (containing about $50 \%$ $\mathrm{PACl})$ and $\varphi \mathrm{COD}_{\mathrm{Mn}}=42 \%\left(\mathrm{COD}_{\mathrm{Mn} 60}=3.52 \mathrm{mg} \mathrm{O} \cdot \ell^{-1}\right)$ with Anikem 4141 (containing about $60 \% \mathrm{PACl}$ ). The highest separation efficiency with respect to turbidity was obtained with aluminium sulphate and the lowest one with blended PACl-based CPE. The best separation efficiency with respect to residual $\mathrm{Al}$ was obtained with aluminium sulphate and $\mathrm{PACl}$. In contrast to aluminium sulphate and $\mathrm{PACl}$, the separation efficiency of the blended PAClbased CPE was found to decrease with increasing dosage rate. Evidently, blended PACl-based CPE did not create conditions for effective removal of the respective pollutants.

Data in Table 3 show that some CPE are cheaper to apply than destabilisation reagents when dosage cost factors alone are compared. When the quality of treated water is also considered, evidently, there is no justification whatsoever for using any CPE at all.

Furthermore, it follows from Table 3 that ferric chloride was not only the most efficient but also, from a dosage-cost point of view, the cheapest hydrolysing reagent. $\mathrm{PACl}$ was found to be both less efficient and, from a dosage-cost point view, also considerably more expensive than aluminium sulphate. Therefore, the use of $\mathrm{PACl}$ is neither technologically nor economically justifiable.

It follows from the foregoing that CPE are considerably less efficient coagulants overall in comparison to hydrolysing reagents and that CPE should not be used as coagulant for treatment of waters with significant organic pollution. Therefore, $\mathrm{CPE}$ is not an equivalent substitute for hydrolysing coagulants. Based on experience, certain CPE may be found to be of some benefit, but only for treatment of waters with insignificant organic pollution.

Figures 14 and 15 show that adjustment of reaction $\mathrm{pH}$ value does not improve quality to which water is treatable by CPE. Consequently, much higher separation efficiencies achieved by destabilisation reagents than those attainable by CPE result from different mechanisms enabling particle aggregation.

The differences in separation efficiencies between hydrolysing reagents and CPE have their origin in the mechanisms by which these reagents aggregate the particles of impurities.

Separable aggregates are formed by two groups of mechanisms:

- The first group is represented by the mechanisms for which the prerequisite of aggregation is destabilisation of particles, i.e. the energy barrier between colliding particles is either totally removed or suppressed to such an extent that it can be forcibly overcome by the high kinetic energy of the colliding particles.

- The second group is represented by the mechanisms for which direct reactions, physical or chemical, take place between the particles of impurities and the particles of coagulant as well as between the particles of impurities and the aggregates already formed.

The first group represents the mechanisms by which hydrolysing reagents function and the second group those by which the CPE function.

The impurities of hydrophobic character are mainly stabilised by a surface, usually negative charge (electric double layer). The impurities of hydrophilic character are stabilised by hydration layer and their negative charge is caused by ionisation of carboxyl and phenolic functional groups (- $\mathrm{COOH}$ and $-\mathrm{OH})$. The stabilisation energy of the particles is concentrated only in certain places, the active centres, which are located on the surface of hydrophobic particles, such as corners and edges, and in the functional groups of hydrophilic particles (organic molecules).

The chemical structure of the particles determines distribution of the active centres on their surface and for a given impurity this is unchangeable. Their physical configuration determines accessibility of the active centres to the particles of hydrolysing reagent. The products of hydrolysis, the hydroxocomplexes, bind themselves onto the particles of impurities just and only in these active centres and neutralise their charge with the charge they carry, thus destabilising them.

The particles of impurities of different composition have their active centres accessible at different $\mathrm{pH}$ values. Their configuration changes depending on the reaction conditions (dosage and $\mathrm{pH}$ ). At low $\mathrm{pH}$ values open configuration predominates and at high $\mathrm{pH}$ values close configurations prevail. In open configuration, the active centres are more accessible than in the close configuration.

Therefore, particle aggregation proceeds easily when the hydrophilic particles are of an open, chain type, or the macromolecule chains unravel due to the optimised reaction conditions and the functional groups become accessible. In contrast, it proceeds with difficulty when the hydrophilic particles are of a chain-like configuration and the functional groups are closed in the molecule.

For these reasons, treatment of surface waters should almost always take place in an acidic $\mathrm{pH}$ range.

\section{Mechanisms of aggregational destabilisation}

The individual mechanisms of aggregational destabilisation can be distinguished as follows (Polasek and Mutl, 1995a):

1 Destabilisation of the particles of impurities by the suppression of their electric double-layer by a simple electrolyte.

2 Destabilisation of the particles of impurities by the specific adsorption of the products of hydrolysis of $\mathrm{Al}$ and $\mathrm{Fe}$ salts accompanied by charge neutralisation.

3 Destabilisation of the particles of impurities by co-ordination reactions between functional groups contained in the particles of impurities and the metal ions of hydroxopolymers, thus changing the magnitude of the charge of the particles of impurities.

4 Formation of inter-particle bridges between the particles of impurities on one hand and the particles of the products of hydrolysis of hydrolysing reagent, or by organic flocculants (polyelectrolytes) on the other hand.

5 Enmeshment of the particles of impurities in a precipitate.

6 Adsorption of the particles of impurities onto the surface of aggregates already formed.

Mechanism 1 is the main mechanism by which the hydrophobic particles are destabilised by reducing their $\zeta$-potential. Mechanism 2 is considered to be most effective for the destabilisation of hydrophobic and mechanism 3 of hydrophilic particles. Hydrolysing reagents destabilise the particles of impurities by means of these mechanisms. In the treatment of natural waters containing mixtures of different impurities, a combination of these basic mechanisms is complemented to a greater or lesser extent by all the other mechanisms mentioned above. In contrast to hydrolysing reagents, mechanism 4 is the basic mechanism by which CPE function, it can be complemented to a greater or lesser extent by mechanisms 5 and 6 only. Due to that, the CPE efficiency for the removal of hydrophilic impurities is almost insignificant and, for these reasons, they are not equivalent substitutes for hydrolysing reagents. 


\section{Conclusions}

1 Some of surface waters in South Africa can be characterised as waters with technologically significant organic pollution. These waters can be treated to a very high quality by a suitable hydrolysing coagulant, but not to any meaningfully good quality by the CPE. None of the CPE was found to be capable of treating water to the same quality as hydrolysing reagents. The CPE were found to be ineffective for the removal of organic pollution and most are also not even capable of treating water to a sparkling clarity. Furthermore, it was found that some of the natural-type CPE are potential sources of objectionable secondary organic pollution.

2 Due to the very low overall treatment process efficiency, no $\mathrm{CPE}$ was found to be an equivalent substitute for hydrolysing coagulants. Therefore, CPE should be used with great caution after a thorough investigation and only for treatment of water with technologically insignificant organic pollution.

$3 \mathrm{PACl}$, the CPE of a synthetic origin and blended Fe-based CPE produce typical coagulation curves. In contrast, no such curves were obtained by CPE of natural origin and blended PAClbased CPE with respect to some of the pollution determinants.

4 The mechanisms of particle aggregation by which hydrolysing coagulants function, is considerably more efficient for the removal of organic impurities than the mechanism of interparticle bridging, by which CPE function. As a result, treatment by CPE is capable of improving only the appearance of water, but not its true quality in any meaningful way.

5 While aluminium sulphate and $\mathrm{PACl}$ were found to be on par with respect to their efficiencies for the removal of turbidity and $\mathrm{Al}, \mathrm{PACl}$ was found to be less efficient for the removal of organic matter.

6 The lower treatment process efficiency attainable by $\mathrm{PACl}$ together with higher coagulant dosage-cost in comparison to aluminium sulphate does not justify replacement of aluminium sulphate with PACl. Such replacement can result in treating water to a considerably poorer quality at increased operating costs in comparison to that attainable by aluminium sulphate.

7 The use of blended CPE is not technologically justifiable. When the use of CPE is essential for plant operation, it is more beneficial to use hydrolysing coagulant on its own and to apply a suitable CPE as an aggregation aid, also on its own, to the most suitable point in the process of particle aggregation.

8 Since the attainable quality of treated water together with possible secondary pollution are dependent on the type of CPE and its dosage, application of any CPE should ALWAYS be preceded by a positive outcome of a thorough evaluation of all aspects influencing treatment process efficiency and the quality of the treated water. Since CPE usually require a greater energy input into the process of aggregation than aggregation by means of hydrolysing reagents, the design of each individual process unit should be thoroughly appraised with respect to its suitability for optimal application of the CPE.

9 The CPE manufacturers and suppliers should not be allowed to hide the quality of their products behind trade names and Health Department Certificates only, thus confusing the proper identification of CPE. They should be compelled to provide, as a rule, a complete technical specification and composition of each CPE supplied under any trade name. Furthermore, they should be compelled to provide simple methods for measuring the content of active components of the CPE (incoming control of product received by the works) and its residue in the treated water.
10 The treated water quality results obtained prove beyond any doubt that the residual turbidity criterion alone used for monitoring and evaluation of waterworks performance does not characterise the true quality of the treated water and should be broadened to include determination of other quality determinants such as residual metal component Me of the coagulant used and organic matter characterised by DOC or $\mathrm{COD}_{\mathrm{Mn}}$ value.

\section{Symbols}

$\mathrm{COD}_{\mathrm{Mn}} \quad$ - chemical consumption of oxygen required for oxidation of the oxidisable substances by potassium permanganate under boiling conditions - it characterises the content of organic matter in drinking water

$\mathrm{COD}_{\mathrm{Mn}}^{\mathrm{RW}}$ - total $\mathrm{COD}_{\mathrm{Mn}}$ value of raw water

$\mathrm{COD}_{\mathrm{Mn}}{ }^{\mathrm{RW}} \mathrm{F}-\mathrm{COD}_{\mathrm{Mn}}$ value of raw water produced by nonseparable particles

$\mathrm{COD}_{\mathrm{Mn} 60}$ - corresponds to total residual content of organic matter remaining in treated water after $60 \mathrm{~min}$ sedimentation

$\mathrm{D}_{\mathrm{A}} \quad-$ applicable coagulant dosage

$\overline{\mathrm{G}}^{\mathrm{A}} \quad$ - square root mean velocity gradient

$\mathrm{Me} \quad$ - metal or metal component of hydrolysing coagulant

$\mathrm{Me}^{\mathrm{RW}} \quad$ - dissolved metal in raw water

$\mathrm{Me}_{60} \quad$ - total residual metal component of hydrolysing reagent remaining in treated water after $60 \mathrm{~min}$ sedimentation

$\mathrm{Me}_{60} \mathrm{~F}$ - residual metal component of hydrolysing coagulant in the treated water produced by nonseparable particles in the $\mathrm{Me}_{60}$ sample

$\mathrm{pH}^{\mathrm{RW}} \quad-\mathrm{pH}$ of raw water

$\mathrm{TOH}_{\mathrm{P}} \quad$ - total organohalogens, potential value

$\mathrm{TOH}_{\mathrm{T}} \quad$ - total organohalogens, terminal value

$\mathrm{Tu} \quad-$ turbidity

$\mathrm{Tu}^{\mathrm{RW}} \quad-$ total turbidity of raw water

$\mathrm{Tu}^{\mathrm{RW}} \mathrm{F} \quad$ - turbidity of raw water produced by nonseparable particles

$\mathrm{Tu}_{60} \quad-$ total residual turbidity remaining in treated water after 60 min sedimentation

$\mathrm{Tu}_{60} \mathrm{~F} \quad-$ residual turbidity of treated water produced by non-separable particles in the $\mathrm{Tu}_{60}$ sample

$\mathrm{t}^{\mathrm{RW}} \quad-$ temperature of raw water

$\varphi_{\mathrm{COD}} \quad-$ separation efficiency of the treatment process with respect to organic pollution.

\section{References}

AJZAWA T, MAGARA Y and MUSAHI M (1990) Problems with introducing synthetic polyelectrolyte coagulants into the water treatment process. Water Supply 8 27-35.

AMY GL and CHADIK PA (1983) Cationic polyelectrolytes as primary coagulants for removing trihalomethane precursors. JAWWA $\mathbf{7 5}$ 527-531.

CARNS KE and PARKER JD (1985) Using polymers with direct filtration. JAWWA 77 (3) 44-49.

GLAZER HT and EDZWALD JK (1979) Coagulation and direct filtration of humic substances with polyethylenimine. Environ. Sci. and Technol. 13 299-305.

GREGORY J and LEE SY (1990) The effect of charge density and molecular mass of cationic polymers on flocculation kinetics in aqueous solution. J. Water SRT - Agua 39 (4) 265-274. 
HEALEY KJ, RICHARDS WN and SMITH BNT (1989) The use of organic polymers as primary coagulants in water treatment and the role of bentonite as coagulant aid. Paper presented at WISA Bienn. Conf., Cape Town.

HOCMAN G (1986) Chemia a karcinogenita (in Slovak) Alfa, VTEL, Bratislava.

KUBEL W (1866) Anleitung zur Untersuchung von Wasser (In German). Vieweg um Sohn, Braunschweig.

MUTL S and POLASEK P(1996) The significance of organic pollution for the treatment of water by coagulation. Paper presented at WISA Bienn. Conf., Port Elizabeth, May 1996.

NARKIS N and REBHUN M (1977) Stoichiometric relationship between humic and fulvic acids and flocculants. JAWWA 69 325-328.

NOZAICK DJ, FREESE SD and THOMPSON P (2000a) Long-term experience in the use of polymeric coagulants for coagulation and flocculation at Umgeni Water. Paper presented at Int. Conf., IAWQ Durban.

NOZAICK DJ, FREESE SD and THOMPSON P (2000b) An evaluation of long-term use of polymeric coagulants at Umgeni Water. Paper presented at Int. WISA Bienn. Conf., Sun City 2000.

PITTER P (1981) Hydrochemie (in Czech). SNTL, Praha.

POLASEK P (1970, 1972) SA Patents.

POLASEK P and MANGEOT LCP (1988) Shortcomings in water treatment practices in South Africa. Paper presented at Int. Water Supply Ass. Semin., KwaZulu, Durban, June.
POLASEK P and MUTL S (1995a) Guidelines to coagulation and flocculation for surface waters. 1: Design principles for coagulation and flocculation systems. PPA, Johannesburg.

POLASEK P and MUTL S (1995b) Guidelines to coagulation and flocculation for surface waters. 2: Evaluation of treatment process efficiency of different waterworks - Case studies. PPA, Johannesburg.

POLASEK P and MUTL S (1997) Treatment process efficiencies of South African waterworks. J. WS and E, June and September.

POLASEK P and MUTL S (1999) Treatability of water with cationic polyelectrolytes. Paper presented at Int. Conf. on Problems in Fluid Mech. and Hydrol., IH-ASCR, Praha.

POLASEK P and MUTL S (2000) To enhanced coagulation. J. IMIESA, Sept., Johannesburg.

POLASEK P and VAN DUUREN FA (1981) The performance results from operation of high-rate clarifiers at Bethlehem Municipal Waterworks. Paper presented at Water Ind. '81, Int. Conf. Brighton, UK.

PRIVATECOMMUNICATIONS (1983) Analysis of water carried out by NIWR, Pretoria.

PRYOR MJ and FREESE SD (1999) Enhanced Coagulation for the Removal of Disinfection by Product Precursors. WRC Report No TT $105 / 98$.

TANAKA TS and PIRBAZARI M (1986) Effects of cationic polyelectrolytes on the removal of suspended particulates during direct filtration. $J A W W A 76$ (12) 57-65.

TUCEK J, CHUDOBA F and KONICEK Z (1977) Zakladni procesy a vypocty v technologii vody (in Czech). SNTL, Praha. 